\title{
Film Growth of Ice by Vapor Deposition at 128-185 K Studied by Fourier Transform Infrared Reflection-Absorption Spectroscopy: Evolution of the OH Stretch and the Dangling Bond with Film Thickness
}

\author{
S. Mitlin and K. T. Leung* \\ Department of Chemistry, University of Waterloo, Waterloo, Ontario N2L 3G1, Canada
}

Received: November 20, 2001; In Final Form: April 10, 2002

\begin{abstract}
The polycrystalline and noncrystalline ice films vapor-deposited at $128-185 \mathrm{~K}$ were investigated by grazingangle Fourier transform Infrared Reflection-Absorption Spectroscopy (RAS). In particular, the polycrystalline ice phase was found above $155 \mathrm{~K}$, whereas the noncrystalline phase was formed below $145 \mathrm{~K}$. The nature of the polycrystalline and noncrystalline ice phases can be differentiated by comparing the respective RA spectra with spectral simulations based on the Fresnel reflection and Mie scattering methods. Furthermore, the $\mathrm{OH}$ stretching band (3800-2800 $\mathrm{cm}^{-1}$ ) exhibits complex behavior as a function of film thickness (from less than $10 \mathrm{~nm}$ to $1500 \mathrm{~nm}$ ), which can be simulated and attributed primarily to the physics of absorption-reflection based on the Fresnel equations for reflection coefficients for parallel- and perpendicular-polarized light in a vacuum-dielectric film-metal system. The spectral evolution of the $\mathrm{OH}$ stretch with the film thickness is found to be similar for both polycrystalline and noncrystalline phases. In addition, spectral features of the incompletely coordinated $\mathrm{OH}$ groups at $3700-3690 \mathrm{~cm}^{-1}$ have been observed for a majority of noncrystalline and polycrystalline ice samples grown under different conditions (e.g., at $185 \mathrm{~K}$ ), which shows that these $\mathrm{OH}$ dangling bonds are an integral part of the surfaces of both noncrystalline and polycrystalline ice phases. For thin films less than $200 \mathrm{~nm}$ thick, both kinds of ice are found to have a comparable amount of $\mathrm{OH}$ dangling bonds. In contrast, the thicker films (with thicknesses greater than $700 \mathrm{~nm}$ ) of the noncrystalline phase contain a noticeably larger amount of $\mathrm{OH}$ dangling bonds than the polycrystalline films of comparable thickness. This thickness dependence of the $\mathrm{OH}$ dangling bond feature suggests that the $\mathrm{OH}$ dangling bonds are located most likely on the external surfaces of the crystalline grains and/or of the ice film itself at larger thicknesses for polycrystalline phase and on the tracery external surface in the case of noncrystalline phase.
\end{abstract}

\section{Introduction}

The physics and chemistry of different low-temperature micro-phases of ice remain to be under intense investigation over the past decade primarily due to the important role that these ice micro-phases play in a variety of chemical processes in the biosphere, ${ }^{1}$ atmosphere, and stratosphere, ${ }^{2,3}$ as well as in interstellar space. ${ }^{4}$ In particular, low-temperature water could be a common medium for a wide range of organic and inorganic chemical processes, often facilitated by external irradiation. The interactions of polymorph phases with the impinging molecules could lead to adsorption, clusterization and chemical modification, as well as diffusion in their original or modified forms into the bulk. The mechanisms of the interactions between lowtemperature water and the adsorbates are therefore expected to depend on the surface properties and dynamics of specific complexes of the micro-phases and the bulk structures that exist under different conditions. The temperature range in which the ice micro-phases could be formed and participate in various chemical processes extends from $10 \mathrm{~K}$ for outer space events to $190-220 \mathrm{~K}$ for stratospheric, and to $220-273 \mathrm{~K}$ for biospheric events.

The structural properties of different noncrystalline and crystalline ice phases and their surfaces have been investigated by a variety of techniques, including X-ray diffraction, 5,6 electron diffraction and microscopy, ${ }^{7,8}$ neutron diffraction and inelastic scattering,,${ }^{9,10}$ helium diffraction, ${ }^{11}$ calorimetry, ${ }^{12}$ and IR and Raman spectroscopies. ${ }^{13-17}$ These studies have shown that condensation of water vapor on a cold substrate at low pressure may lead to, depending upon the deposition conditions, the formation of different noncrystalline structures below $130 \mathrm{~K}$ and of polycrystalline ice (pc-ice) polymorphs, Ic (cubic ice), and Ih (hexagonal ice), at a more elevated temperature.

Noncrystalline structures are metastable with respect to crystalline phases Ic and Ih and consequently their formation and existence are kinetically controlled. Upon warming, noncrystalline ice (nc-ice) transforms irreversibly to the Ic phase over a relatively wide range of transition temperature of 140$160 \mathrm{~K} .^{18}$ This crystallization process, which begins at temperature just above the glass-to-liquid transition, has been noted as incomplete because fragments of the noncrystalline microphases could persist in coexistence metastably with Ic over the temperature range $140-210 \mathrm{~K}$, and with both Ic and Ih above $160 \mathrm{~K}$. The nature of these noncrystalline micro-phases remains a subject of intense debate. ${ }^{6,7,18}$ Furthermore, irreversible transformation from Ic to Ih has been observed over a wide temperature range of $160-240 \mathrm{~K}$, which has been attributed to the dependence of the crystallization temperature on the size of the cubic ice crystals. ${ }^{19}$ These observations suggest that the ice phase at temperature range between $\sim 135 \mathrm{~K}$ (the onset of the glass-to-liquid transformation) and $240 \mathrm{~K}$ (completion of Ic-to-Ih transformation) consists of noncrystalline and crystalline micro-phases dynamically in coexistence, with an increasing proportion of the latter phase with increasing temperature. The structural evolution of the ice micro-phases with increasing 
temperature therefore includes phase transformation from a noncrystalline phase to Ic and then to Ih, coupled with morphological and interfacial changes, in which rearrangement of hydrogen bonds occurs at multiple internal and external interfaces. The reconstruction processes that accompany the phase transformations are thought to be responsible for the kinetically controlled character of the phase transformation. Clearly, the nature of the ice micro-phases at a particular temperature will have an enormous impact on the adsorption properties of low-temperature water and the status of foreign molecules in the ice structure. On the other hand, foreign molecules adsorbed on the surface or trapped in the bulk of such complexes could in turn affect the dynamics of phase transformation and especially the reconstruction processes themselves. Indeed, very little is known about the surface characteristics of the complexes on the ice micro-phases in the temperature range $140-210 \mathrm{~K}$.

Noncrystalline solid water can exist in two distinct forms: high-density amorphous ice (with its density $\rho$ greater than 1.1 $\mathrm{g} / \mathrm{cm}^{3}$ ) and low-density amorphous ice (with $\rho \approx 0.94 \mathrm{~g} / \mathrm{cm}^{3}$ ). ${ }^{20}$ The proposed local structure of the more compact high-density amorphous ice is in fact quite similar to the low-density amorphous ice particularly in terms of the oxygen-oxygen radial distribution function but with additional water molecules presumably occupying interstitial sites. ${ }^{18,21}$ Primarily on the basis of the measurements of the surface area ${ }^{22}$ and the density of the ice films ${ }^{23}$ and on the IR studies of water microclusters and ice films, ${ }^{17}$ it was concluded that the low-density amorphous ice (obtained by water vapor deposition below $130 \mathrm{~K}$ ) is a highly porous open network with a surface area of $150-500 \mathrm{~m}^{2} / \mathrm{g}$ (due to the abundance of nanoscale-sized pores) and therefore a significant concentration of noncompensated surface $\mathrm{OH}$ groups. By comparing the amounts of surface areas of thin nc-ice and pc-ice films (thickness less than 250 bilayers) deposited at 22$145 \mathrm{~K}$ by effusive beam dosing at different incident angles and by ambient dosing, Stevenson et al. showed that the surface area of the nc-ice deposits increases with a larger incident angle (from the normal direction) in qualitative accord with the predictions of the ballistic deposition model. ${ }^{24}$ This model takes into general account of the interplay between roughening caused by randomness of deposition, smoothing by surface diffusion, and nonlocal effects generated by shadowing. ${ }^{25}$ The unusually large values of apparent surface area obtained by ambient dosing at $22 \mathrm{~K}\left(2700 \mathrm{~m}^{2} / \mathrm{g}\right)$ and $77 \mathrm{~K}\left(640 \mathrm{~m}^{2} / \mathrm{g}\right)$ along with the linear increase of the surface area with deposition time led Stevenson et al. to propose that the internal surface is directly connected to the external surface of the film. This observation is consistent with the open network model for the morphology of the nc-ice film, in which the amount of the internal surface would be directly proportional to the volume of the phase. Furthermore, the $\mathrm{N}_{2}$ uptake by the ice films deposited by beam dosing at different incident angles above $90 \mathrm{~K}$ was found to be the same as that by the pc-ice films deposited at $145 \mathrm{~K},{ }^{24}$ which can be explained by enhanced surface diffusion at a higher temperature. With increasing deposition temperature, the surface area of the ice film was also found to be greatly reduced, ${ }^{24}$ suggesting the isolation of the internal surface from the impinging gas molecules, whereas the areas of the external surfaces of nc-ice and pc-ice films remain the same. Furthermore, Rowland et al. demonstrated the presence of open micropores in the nc-ice micro-particles by FTIR spectral observation of OH/OD dangling bonds (db's) and their chemical shifts as the result of $\mathrm{N}_{2}$ adsorption. ${ }^{17}$ Specifically, the migration of $\mathrm{N}_{2}$ molecules into the micropores during annealing of the nitrogen-nc-ice system from 10 to $22 \mathrm{~K}$ and reversible adsorption-desorption of the adsorbate molecules in the volume of the micropores at temperatures $75-80 \mathrm{~K}$ suggest that these pores are connected to the external surface and can be accessed by molecules from the environment. The porous character of low-density amorphous ice is clearly caused by the thermo-kinetics of deposition, because the incoming water molecules that adsorb to the surface of the interface with unity sticking coefficient initially ${ }^{23}$ could lose most of their kinetic energy well before reaching the most stable sites. ${ }^{26}$

Of particular interest is the microstructure of internal and external surfaces of low-density amorphous ice micro-phases. In particular, IR spectroscopy, with and without the grazingangle RA technique, has been applied successfully to study the surface properties of microclusters and vapor-deposited ice films. Transmittance IR measurements of low-temperature (10-15 K) amorphous microclusters of $\mathrm{H}_{2} \mathrm{O}$ and $\mathrm{D}_{2} \mathrm{O}$, together with molecular dynamic simulations of their surfaces, by Devlin and co-workers ${ }^{15-17}$ have shown that the external and internal surfaces of these materials contain two- and three-coordinated water molecules. Part of these molecules have a noncompensated $\mathrm{OH} \mathrm{db}$, whereas others have an oxygen atom as a noncompensated site. Annealing the clusters at $60 \mathrm{~K}$ and further to $120 \mathrm{~K}$ led to complete disappearance of the $\mathrm{db}$ features associated with two- and three-coordinated surface molecules, respectively. These observations were explained in terms of reduction in the amount of the internal surface..$^{15-17}$

Using FTIR RAS, Callen et al. ${ }^{27}$ detected OD db's on the outer surface of a 1.5-monolayer (ML) $\mathrm{D}_{2} \mathrm{O}$ film at $130 \mathrm{~K}$ and $\mathrm{OH}$ db's (at $3699 \mathrm{~cm}^{-1}$ ) on the surface of a 5-ML $\mathrm{H}_{2} \mathrm{O}$ film deposited above the $\mathrm{D}_{2} \mathrm{O}$ film. The $\mathrm{OD} \mathrm{db}$ feature located at $2731 \mathrm{~cm}^{-1}$ was attributed to three-coordinated surface molecules. Its intensity was found to increase with increasing water exposure and become saturated at 3 MLs, above which coverage this signal was overwhelmed by the neighboring main peak of the OD stretch. The absence of the $\mathrm{db}$ feature corresponding to two-coordinated molecules shows that near $130 \mathrm{~K}$ newly adsorbed water molecules have sufficient energy for local surface reconstruction giving rise to the production of triply coordinated sites. Similar behavior of the OD db was also observed by Horn et al. ${ }^{28}$ on a much thicker $\mathrm{D}_{2} \mathrm{O}$ amorphous ice film deposited at $110 \mathrm{~K}$. Both of these studies ${ }^{27,28}$ have suggested that the $\mathrm{OD} / \mathrm{OH} \mathrm{db}$ 's are most likely located on the outer surface of the ice films, after taking in account of the aforementioned signal behavior as a function of film thickness. On the other hand, a detailed investigation of the behavior of $\mathrm{OH} \mathrm{db}$ in the vapor-deposited ice samples between 94 and 120 $\mathrm{K}$ by Zondlo et al. has shown that the majority of the $\mathrm{OH} \mathrm{db}$ 's are most likely located on the surface of micropores inside the bulk of amorphous ice. ${ }^{29}$ The intensity of the $\mathrm{OH} \mathrm{db}$ feature was found to increase almost linearly with increasing film thickness up to $200-250 \mathrm{~nm}$ at $94 \mathrm{~K}$, and level off at $0.03-$ 0.05 integrated absorption unit (AU) upon further film growth to $500 \mathrm{~nm}$. This spectral saturation occurs as the result of the physics of RA and not related to the amount of the $\mathrm{OH}$ db's (see below). Furthermore, the $\mathrm{db}$ feature appeared to weaken at a higher deposition temperature. At $120 \mathrm{~K}$ and deposition pressure below $1 \times 10^{-6}$ Torr, the peak intensity became very small (below 0.01 integrated $\mathrm{AU}$ ) and decreased with further increase in the film thickness. Zondlo et al. further concluded that the lower substrate temperature and faster deposition rate favored the production of open water network with abundance of micropores covered by the OH db's. ${ }^{29}$ These FTIR-RAS studies $^{27-29}$ are consistent with the model that for thin $(<50$ 
nm) amorphous ice film (obtained by slow vapor deposition above $110-120 \mathrm{~K}$ ), the internal surface is small, in which case the db signal, if detectable, comes predominantly from the $\mathrm{OH} /$ OD groups located on the smooth external surface. A faster deposition rate at these temperatures leads, most likely, to the production of porous water network with relatively welldeveloped internal surface. Under these growth conditions, the $\mathrm{db}$ signal originates primarily from the free $\mathrm{OH} / \mathrm{OD}$ groups located on the surface of the micropores. ${ }^{29}$

To investigate the surface chemistry of organic molecules on ice films, we record in the present work FTIR-RA spectra of ice films grown by vapor-deposition at $128-185 \mathrm{~K}$ and differentiate between pc-ice and nc-ice phases by modeling based on the Fresnel reflection and Mie scattering theories. In a follow-up paper, we will examine the interaction of these ice micro-phases with organic molecules of environmental interest, such as acetone. ${ }^{30}$ In particular, the $\mathrm{OH}$ stretch mode is of special interest because it is the most sensitive IR mode to the structural organization of the molecular network in ice. The IR-RA spectra of ice micro-phases, especially in the $\mathrm{OH}$ stretch region, generally show a significant difference from their transmittance analogues. ${ }^{13}$ Although this difference is due to the inherent characteristics of grazing-angle IR-RAS of strongly absorbing media, it has seriously complicated the identification of the ice micro-phases present under different temperature conditions. Our present calculations, based on the Fresnel equations for reflection coefficients and the Mie scattering method for crystalline and noncrystalline ice phases, give reasonable agreement between the observed and simulated IR-RA spectra. These calculations could therefore be used to provide useful insights for differentiation between crystalline and noncrystalline ice phases, given known optical constants of these materials at the temperature range of interest. Moreover, the temperature range covered in the present study $(128-185 \mathrm{~K})$ is also of special interest because it includes the transition temperature range between noncrystalline and polycrystalline phases (140-160 K). Furthermore, the temperature region near $190 \mathrm{~K}$ covers the important atmospheric chemistry region, of which the $\mathrm{OH} \mathrm{db}$ feature can be used as a sensitive probe of the surface properties of pc-ice.

\section{Experimental Section}

The FTIR-RAS experiments were conducted in a home-built UHV chamber evacuated by a $250 \mathrm{~L} / \mathrm{sec}$ turbo-molecular pump to a base pressure of better than $6 \times 10^{-9}$ Torr. Ice was condensed from water vapor on an optically flat polycrystalline $\mathrm{Cu}$ disk (2.25-in. diameter) mounted on a four-motion manipulator. Figure 1 shows schematically the glancing-incidence optical arrangement of the experiment, which allows signal optimization at zero path difference by easy adjustment of the position of the target with respect to the optical path of the infrared beam. The 1.5-in. diameter infrared beam from a Bruker Equinox 55 FTIR spectrometer equipped with an air-cooled Globar source was directed onto the $\mathrm{Cu}$ disk at $83^{\circ}$ from the surface normal by a focusing $90^{\circ}$ parabolic mirror with a 16 in. focal length. The specularly reflected light was collected by a second identical parabolic mirror (with a 16-in. focal length) positioned on the opposite side of chamber, and finally focused by a 1.7-in.-focal-length parabolic mirror onto a liquid nitrogen cooled Mercury Cadmium Telluride detector (energy range: $7000-600 \mathrm{~cm}^{-1}$; sensitivity $\left.>2.5 \times 10^{10} \mathrm{~cm} \mathrm{~Hz}^{1 / 2} / \mathrm{W}\right)$. Two $\mathrm{CaF}_{2}$ optical windows mounted on differentially pumped 8-in. conflat flanges were used to provide passage of the infrared beam onto the sample inside the UHV chamber. The optical

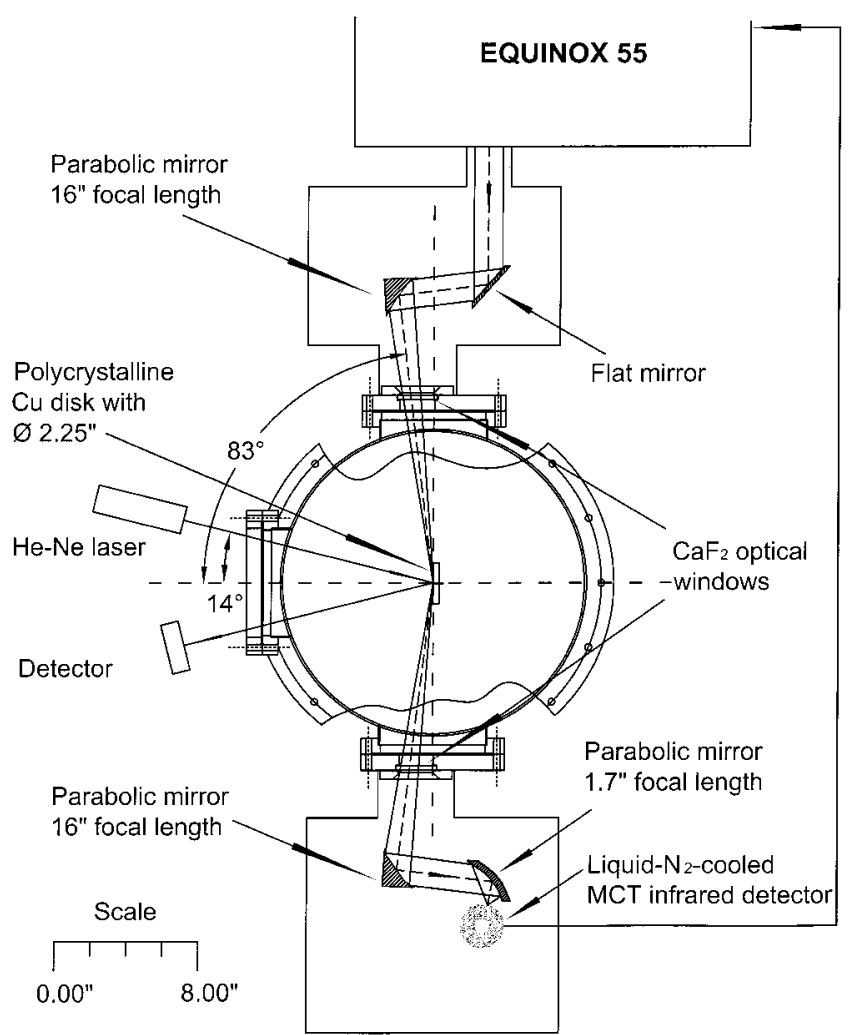

Figure 1. Schematic layout of the optical arrangement of a reflectionabsorption apparatus. Only three of the 19 ports of the center ultrahigh vacuum chamber (with a base vacuum below $6 \times 10^{-9}$ Torr) relevant to the experiment are shown. Two of the ports that are used to house the $\mathrm{CaF}_{2}$ windows are differentially pumped. The FTIR spectrometer (Bruker Equinox 55) and the two aluminum boxes that house the transfer optics and the Mercury Cadmium Telluride (MCT) detector are flushed with dry $\mathrm{N}_{2}$ gas continuously to minimize ambient contamination.

path outside the UHV chamber was enclosed in aluminum boxes purged with dry $\mathrm{N}_{2}$ gas to remove spectral interference due to absorption peaks of water vapor in the ambient environment.

Cooling of the $\mathrm{Cu}$ substrate was facilitated by two copper braids directly welded to a liquid nitrogen cooled stainless steel/ copper dewar inside the UHV chamber. During cooling, the dewar also functioned as a cryopump, lowering the chamber pressure to $3 \times 10^{-9}$ Torr. The substrate could be annealed to a higher temperature above the lowest temperature achievable in the present setup $(128 \mathrm{~K})$ by a resistance heater imbedded in the backside of the $\mathrm{Cu}$ disk under the control of a temperature controller. The substrate temperature was measured by two K-type thermocouples mechanically fastened to the front face of the substrate. The precision of our relative temperature measurement was better than $\pm 2{ }^{\circ} \mathrm{C}$, whereas the uniformity of the temperature across the sampling area of the substrate was found to be better than $5{ }^{\circ} \mathrm{C}$.

Ice film with thicknesses up to $1.5 \mu$ was deposited by backfilling the entire chamber with water vapor using a precision leak valve. Water (Millipore) was purified by repeated freezepump-thaw cycles prior to use. Pressure measurement was obtained by an uncorrected ionization gauge. The thickness of the ice film and the corresponding deposition rate have been estimated by observing the optical interference fringes of a $\mathrm{He}-$ $\mathrm{Ne}$ laser beam reflected off the sample using a phototransistor as the detector. Details of the optical interference method have been described elsewhere. ${ }^{11,14,29}$ It should be noted that the laser interference method provides information about the film thickness for a very small area (of typically $1-2 \mathrm{~mm}$ diameter as 
defined by the illuminating laser spot size) in comparison with the total surface covered by ice, from which the FTIR-RA spectra are taken. Using a laser source with an adjustable beam size (1-10 $\mathrm{mm}$ diameter), Brown et al. showed that the thickness of the ice film deposited on $\mathrm{Ru}(001)$ was uniform over this area range. ${ }^{23}$ In our experiment, the substrate surface was polycrystalline and relatively rough on a microscopic scale, which could introduce thickness nonuniformity. Since the sampling area was quite large (approximately the size of the target or $25 \mathrm{~cm}^{2}$ ), the resulting spectra of the as-grown ice film represent the signal averaged over the entire area of the ice film with possible nonuniform thickness. With the sample held at $131 \mathrm{~K}$, the initial deposition rate (after a typical induction period of $1 \mathrm{~min}$ ) was estimated to be $0.43 \mathrm{~nm} / \mathrm{sec}$ at $1 \times 10^{-6}$ Torr ambient pressure or $2 \mathrm{~nm} / \mathrm{sec}$ at $5 \times 10^{-6}$ Torr. The deposition rate was found to decrease slightly with increasing film thickness. It should be noted that the sensitivity of the optical interference method is limited in the case of very thin films and for films with thickness that satisfies the conditions of constructive and destructive interference. ${ }^{29}$

During deposition of the ice film at a selected temperature, FTIR-RA spectra of the growing film were collected, unless stated otherwise, over a 20 -second period by co-adding 10 scans at $10 \mathrm{kHz}$ scanner velocity (or 40 scans at $40 \mathrm{kHz}$ ) at a preset spectral resolution of $2 \mathrm{~cm}^{-1}$, or alternatively 12 scans at 80 $\mathrm{kHz}$ at $0.5 \mathrm{~cm}^{-1}$ resolution. Background spectra over 5000$1000 \mathrm{~cm}^{-1}$ were collected immediately before the water exposure for the bare $\mathrm{Cu}$ surface with 1000 scans at the respective resolution settings. Spectral data are presented in the dimensionless absorbance unit, $\mathrm{AU}=-\log \left(R / R_{0}\right)$, where $R / R_{0}$ is the ratio of reflectance of the $\mathrm{Cu}$ substrate with and without the ice film.

\section{Spectral Simulations}

In general, the film thickness can have a significant effect on the shape, frequency position and spectral intensity of the RA bands, and these effects have been discussed in detail by Greenler ${ }^{31}$ and Decius and Hexter. ${ }^{32}$ McIntyre and Aspens have used the Fresnel equations for reflection coefficients for paralleland perpendicular-polarized light to simulate the RA spectra of an absorbing dielectric film. ${ }^{33}$ First derived for a homogeneous dielectric film, these equations have been extended and written in modified form to describe reflection-absorption of light in a vacuum-absorbing dielectric film-metal system. ${ }^{34}$ To explain the splitting of the $\mathrm{OH}$ stretch in the RA spectra not found in the transmittance spectra, Horn et al. applied a similar set of equations to simulate the IR-RA spectra of thick pc-ice films. ${ }^{35}$ In the present work, we also apply the Fresnel equations for a vacuum-ice-copper system. For the spectral region of $6962-482 \mathrm{~cm}^{-1}$, the values of real $n$ and imaginary $k$ parts of the complex refractive index of the $j$-th layers $\left(\tilde{n}_{j}=n_{j}-i k_{j}\right)$ used in the present simulation for pc-ice are those derived by Toon et al. for ice films deposited at $163 \mathrm{~K}$ over a wide range of thicknesses from $500 \mathrm{~nm}$ to $30 \mu{ }^{36}$ It should be noted that the nature of the ice phase in this temperature region remains controversial. Although Toon et al. have shown that their derived optical constants are close to those for hexagonal ice, others have suggested that cubic ice is also a plausible component for the ice films grown in this temperature range. ${ }^{37}$ Moreover, the presence of noncrystalline micro-fragments cannot be ruled out. ${ }^{7,18}$ For nc-ice, Fresnel simulations are carried out using the corresponding values of $\mathrm{n}$ and $\mathrm{k}$ for amorphous ice films deposited at $77 \mathrm{~K}$ reported by Leger et al. ${ }^{38}$ Optical constants of $\mathrm{Cu}$ at room temperature compiled by Palik et al. ${ }^{39}$ are used

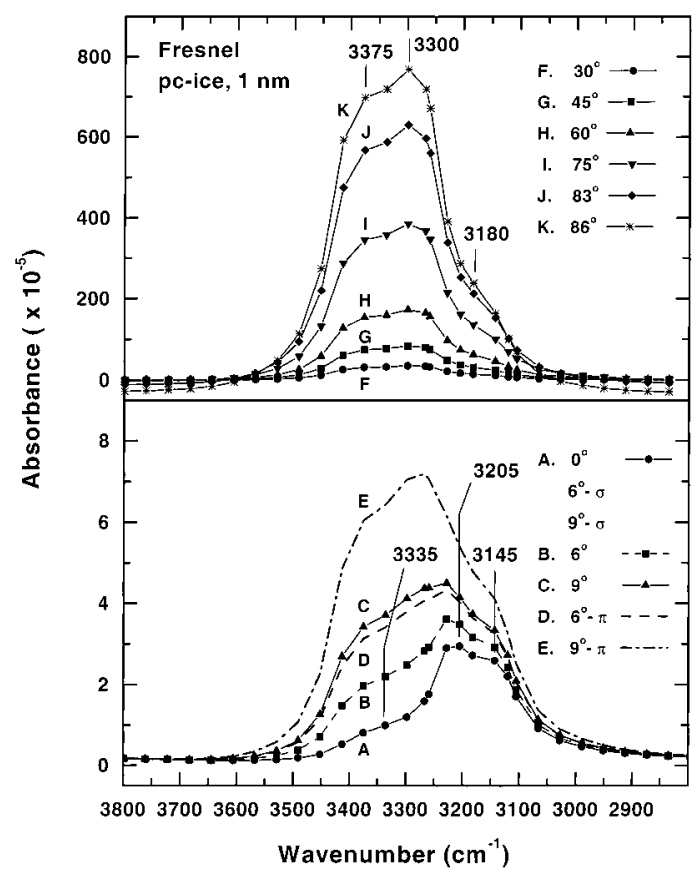

Figure 2. Fresnel spectra of a pc-ice film with thickness of $1 \mathrm{~nm}$ (using optical constants obtained for films deposited at $163 \mathrm{~K}^{36}$ ) for nonpolarized light at different incident angles: (A) $0^{\circ}$ or normal incidence, (B) $6^{\circ}$, (C) $9^{\circ}$, (F) $30^{\circ},(\mathrm{G}) 45^{\circ},(\mathrm{H}) 60^{\circ}$, (I) $75^{\circ}$, (J) $83^{\circ}$, and (K) $86^{\circ}$. The $\sigma$-polarized components of the Fresnel spectra for incident angles of $6^{\circ}$ and $9^{\circ}$ are the same as curve $\mathrm{A}$, whereas the corresponding $\pi$-polarized components are shown as curves $\mathrm{D}$ and $\mathrm{E}$, respectively.

to generate the $(n, k)$ constants of $\mathrm{Cu}$ at the same wavenumbers as the set of complex refractive indexes $\tilde{n}_{j}$ of the ice reported in the literature. Given the very small value of the magnetic susceptibility for $\mathrm{Cu}\left(-5.5 \times 10^{-6} \mathrm{cgs}\right),{ }^{40}$ the magnetic permeability of $\mathrm{Cu}$ is set to unity in our calculations. The calculations of the RA spectra of the pc-ice and nc-ice films with different thickness parameters are performed by using MathCAD 7 software (MathSoft Engineering and Education, Inc.) and our own code (written in $\mathrm{C}$ language) for an incident angle of $83^{\circ}$ in a specular reflection geometry. The calculated spectra are plotted as absorbance unit (AU) versus wavenumber $\left(\mathrm{cm}^{-1}\right)$, where $\mathrm{AU}$ is defined in an expanded form as

$$
\mathrm{AU}=\log \left[\left(R_{0 \sigma}+R_{0 \pi}\right) /\left(R_{\sigma}+R_{\pi}\right)\right]
$$

with $R_{0} \sigma, \pi$ and $R_{\sigma, \pi}$ as the reflectance of $\sigma$ - or $\pi$-polarized light from the vacuum-Cu system (i.e., the bare substrate without ice) and vacuum-ice-Cu system (the substrate deposited with ice), respectively. These calculated spectra are referred as Fresnel spectra in the present work. As in the Fresnel notation, the $\sigma-$ and $\pi$-polarizations are defined with the respect to the plane of incidence (which corresponds to the plane perpendicular to the metal surface that contains the propagation vectors of the incident, reflected and refracted waves). If the electric field vector of the incidence wave is normal to the plane of incidence (i.e., parallel to the metal surface), then such a polarization is denoted as $\sigma$-polarization. On the other hand, when the electric field vector of the incidence wave is parallel to the plane of incidence (i.e., normal to the metal surface), $\pi$-polarized wave is obtained.

To illustrate the importance of the reflection geometry, we show in Figure 2 the calculated RA spectra of the $\mathrm{OH}$ stretch region for a 1-nm-thick pc-ice film as a function of the incident angle based on the Fresnel model. Because the normal incidence spectrum is analogous to the transmittance IR spectrum, Figure 
2 shows, in effect, the changes in the spectral features from the transmittance mode to RA mode. In particular, the normal incidence spectrum shows three discernible features at 3145 , 3205 , and $3335 \mathrm{~cm}^{-1}$ (Figure 2, curve A) to be in good agreement with the experimental transmittance spectrum reported by Buch and Devlin. ${ }^{41}$ With increasing angle of incidence, the low-frequency shoulder of the $\mathrm{OH}$ stretch at 3145 $\mathrm{cm}^{-1}$ is blue-shifted to $\sim 3180 \mathrm{~cm}^{-1}$ with a notable loss in relative intensity while the peak maximum located originally at $3205 \mathrm{~cm}^{-1}$ appears to move to $3300 \mathrm{~cm}^{-1}$. The highfrequency shoulder at $3335 \mathrm{~cm}^{-1}$ strengthens significantly and is blue-shifted to $\sim 3375 \mathrm{~cm}^{-1}$. Although there is essentially no change in the reflectivity of the vacuum-ice interface in this spectral region and in the absorption profile of the $\sigma$-polarized component (Figure 2, curve A), dramatic changes in the absorption profile of the $\pi$-polarized component are observed (Figure 2, curves D and E), which accounts for the changes in the shape of the overall band from $0^{\circ}$ to $15^{\circ}$. The evolution of the absorption profile is due to excitation of the longitudinal lattice modes by the electric field component of the incoming radiation perpendicular to the surface as a function of the nearnormal incident angle. ${ }^{42}$ This excitation occurs at higher frequencies than the transverse excitation and is clearly absent in the transmittance (or normal incidence) mode. ${ }^{32}$ Furthermore, increasing the incident angle above $15^{\circ}$ (toward more glancingangle incidence) significantly increases the intensity of the spectrum without affecting the general shape (Figures 2, curves $\mathrm{F}-\mathrm{K}){ }^{31}$ Evidently, the shape of the spectrum (determined predominantly by longitudinal excitations) is not particularly sensitive to the incident angle in the glancing incidence regime, and the experimental sampling angle $\left(83^{\circ}\right)$ used in the present work provides near optimal spectral intensity.

The physics of reflection-absorption for a triple-medium system determines the dramatic differences in the $\sigma$ - and $\pi$-polarized RA spectra for a wide range of film thicknesses. Specifically, the absorbance of the $\sigma$-polarized light is negligible for a certain range of film thicknesses due to cancellation of the electric field in the spatial region by the metal. ${ }^{29,31,33,34}$ The extent of this region depends primarily on the incident angle and the dielectric properties of the light-adsorbing layer. In the case of a thin ice film on the metal surface, the Fresnel model shows that reflection-absorption of the $\sigma$-polarized light is negligible for a film thickness up to $200 \mathrm{~nm}$, which also suggests that vibrational modes with transition dipole moment parallel to the metal surface would remain undetectable until this critical thickness has been reached. This conclusion is particularly important for spectral observation of the $\mathrm{OH} \mathrm{db}$ 's, because any $\mathrm{OH} \mathrm{db}$ oriented in parallel with the metal surface is undetectable by RA spectroscopy in the case of thin films (see Figure $3 \mathrm{~d}$ below). In contrast, the absorbance of $\pi$-polarized light by thin films is strongly enhanced due to significant amplification of the electric field in the vicinity of the metal surface.

In addition, the interference patterns in the transparent spectral region of ice away from the observed resonances can be described by two-beam interference produced by reflection from two parallel interfaces. ${ }^{34,43}$ In the case of relatively thick films, the interference patterns are observed over the entire spectral region of 5000-1000 $\mathrm{cm}^{-1}$, and the corresponding absorption maxima are seen to travel from the higher to lower frequencies with increasing film thickness. As shown by Robinson et al., ${ }^{43}$ there are two sets of interference patterns, which are associated with destructive interference of $\sigma$ - and $\pi$-polarized components of the infrared light. In accord with these earlier results, ${ }^{43}$ our present work shows that the $\sigma$-patterns in the $5000-1000 \mathrm{~cm}^{-1}$
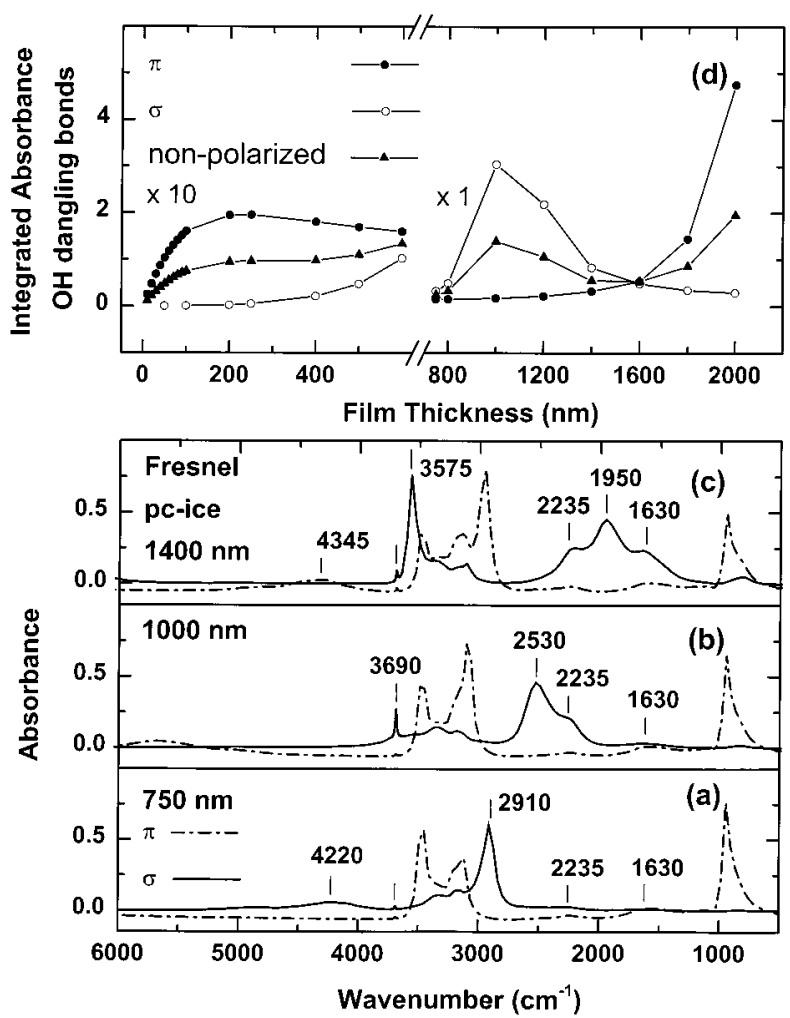

Figure 3. Fresnel spectra of pc-ice films with thicknesses of (a) 750 $\mathrm{nm}$, (b) $1000 \mathrm{~nm}$, and (c) $1400 \mathrm{~nm}$. The dependence of the calculated integrated absorbance of the $\mathrm{OH}$ dangling bond signal on the film thickness is summarized in (d). The Fresnel spectra were calculated with the optical constants obtained for films deposited at $163 \mathrm{~K}$ by Toon et al. ${ }^{36}$ and have been modified by eq 2 using $\nu_{\mathrm{OH}}=3690 \mathrm{~cm}^{-1}$ and a damping constant $\gamma$ of $15 \mathrm{~cm}^{-1}$.

optical window exhibit absorption maxima starting with a film thickness of $350 \mathrm{~nm}$, whereas the corresponding features of the $\pi$-patterns appear at thicknesses above $750 \mathrm{~nm}$. Moreover, the emergence of interference pattern in the optical region of any vibrational mode of ice causes considerable amplification in the intensity of the band. To simulate the dependence of the integrated intensity of the $\mathrm{OH}$ db's on the film thickness, we modified the optical indexes of the crystalline ice obtained by Toon et al. ${ }^{36}$ by inclusion of the $\mathrm{OH}$ db vibrational mode at $v_{\mathrm{OH}}=3690 \mathrm{~cm}^{-1}$ with a damping constant $\gamma$ of $15 \mathrm{~cm}^{-1}$. Furthermore, the $\mathrm{OH} \mathrm{db}$ intensity is artificially enhanced by arbitrarily setting the integrated absorptivity $\left(\rho \pi^{2}=6.86 \times 10^{3}\right.$ $\mathrm{cm}^{-2}$ ) to $0.1 \%$ of the integrated Lambert absorptivity of the $\mathrm{OH}$ stretching mode obtained from Bertie et al. ${ }^{13}$ This simulation treats the $\mathrm{OH}$ db's as an integral part of the ice structure and the amount of $\mathrm{OH}$ db's is proportional to the ice film thickness. The modified dielectric function $\epsilon$ of the resulting ice structure was calculated in accordance with Klein and Furtak ${ }^{44}$ as follows

$$
\epsilon=\epsilon_{0}+\frac{\rho\left(\frac{\epsilon_{0}+2}{3}\right)^{2}}{v_{\mathrm{OH}}^{2}-\left(\frac{\epsilon_{0}+2}{3}\right)\left(\frac{\rho}{3}\right)-v^{2}+i \nu \gamma}
$$

where $\rho=\left(1 / \pi^{2}\right) \int K(v) d v$, and $\mathrm{K}(v)$ is the Lambert absorptivity. $\epsilon_{0}$ is the dielectric function of pc-ice calculated from the data of Toon et al. ${ }^{36}$ The calculations show that the destructive $\sigma$-polarized interference feature travels from $4220 \mathrm{~cm}^{-1}$ (Figure 3a) to $3575 \mathrm{~cm}^{-1}$ (Figure 3c) as the thickness is increased from 750 to $1400 \mathrm{~nm}$. The passage of this $\sigma$-polarized feature over the optical window of the $\mathrm{OH} \mathrm{db}$ band at $3690 \mathrm{~cm}^{-1}$ (Figure 
$3 b)$ causes the amplification in the integrated intensity of the $\mathrm{OH} \mathrm{db}$ signal as summarized in Figure $3 \mathrm{~d}$. Once the $\sigma$-interference feature passes over, the $\mathrm{OH} \mathrm{db}$ signal returns to its normal intensity. Furthermore, the passage of a second destructive $\sigma$-polarized interference feature, which travels from $2910 \mathrm{~cm}^{-1}$ (Figure 3a) to $1950 \mathrm{~cm}^{-1}$ (Figure 3c) over the same thickness range, causes significant amplification in the intensities of the combination band (at $2235 \mathrm{~cm}^{-1}$ ) and bending band (at 1630 $\mathrm{cm}^{-1}$ ). Figure $3 \mathrm{~d}$ also shows that the integrated intensities of $\mathrm{OH} \mathrm{db}$ feature for the $\pi$-polarized and nonpolarized waves increase linearly with the film thickness up to $100 \mathrm{~nm}$ and level off at greater thicknesses due to the physics of reflectionabsorption. This spectral dependence on the film thickness is in agreement with the experimental data of Zondlo et al. ${ }^{29}$ The integrated intensity of the $\mathrm{OH} \mathrm{db}$ feature for $\pi$-polarization remains nearly constant in the thickness range $200-1200 \mathrm{~nm}$, despite the increase in the amount of the $\mathrm{OH}$ db's assumed in the model. The marked increase in the integrated intensity for thicknesses above $1600 \mathrm{~nm}$ (Figure 3d) is evidently caused by emergence of a destructive $\pi$-polarized interference pattern, which travels from $4345 \mathrm{~cm}^{-1}$ to a lower frequency (Figure $3 c)$.

In cases where flat interfaces are not realized, the Mie scattering model is used. ${ }^{34}$ In the present work, Mie scattering calculations are performed for both pc-ice and nc-ice and found to be especially useful for the simulation of the experimental spectra of pc-ice during the early stage of deposition when the ice phases are presumably composed of microcrystals that scatter the IR light. The algorithm for the Mie scattering code used to generate the present Mie spectra has been given by Bohren and Huffman. ${ }^{45}$ The optical constants for pc-ice used in the Mie calculations are those for the Ih ice obtained at $210 \mathrm{~K}$ reported by Clapp et al. ${ }^{46}$ while the corresponding optical constants used for nc-ice are those obtained at $77 \mathrm{~K}$ by Leger et al. ${ }^{38}$

\section{Results and Discussion}

4.1 Polycrystalline Ice Deposition at 155-185 K. Figure 4a shows the experimental FTIR-RA spectra of the initial stage of water deposition at $5 \times 10^{-7}$ Torr with the $\mathrm{Cu}$ substrate held at $160 \mathrm{~K}$, which correspond approximately to $10 \mathrm{~s}$ (Figure 4a, curve A) and $30 \mathrm{~s}$ (Figure 4a, curve B) into the phase formation. These spectra are compared with the Fresnel spectrum for pcice with a film thickness of $0.5 \mathrm{~nm}$ (Figure $4 \mathrm{a}$, curve C) and an Mie spectrum for hexagonal ice spheres with a $10 \mathrm{~nm}$ diameter (Figure 4a, curve D), after appropriate normalization. In the latter calculation, the size of the Mie scatterers is arbitrarily chosen to be small because the calculated Mie spectrum is found to be insensitive to the diameter of the scatterer as long as it is much smaller than the wavelength of the incident light. Evidently, there is a significant difference between the experimental and Fresnel spectra. In particular, the $\mathrm{OH}$ stretch band for the Fresnel spectrum (Figure $4 \mathrm{a}$, curve $\mathrm{C}$ ) is blue-shifted by $\sim 45 \mathrm{~cm}^{-1}$ and has a different shape from the experimental spectra (Figure 4a, curves A-B). On the other hand, the Mie spectrum (Figure 4a, curve D) is found to be in good accord (in shape) with the experimental spectra (Figure 4a, curves A-B), which suggests that the ice deposit is heterogeneous and consists predominantly of small particles that scatter the IR light. For the initial steps of the ice phase formation, the production of crystalline nuclei, instead of a uniform film, is therefore confirmed. This observation is consistent with the general tendency to minimize the surface area of a newly forming phase. As suggested by Mayer and Pletzer, ${ }^{47}$ the formation of the primary crystalline ice nuclei may have already occurred, at least partially, in the gas phase near the cold substrate surface.

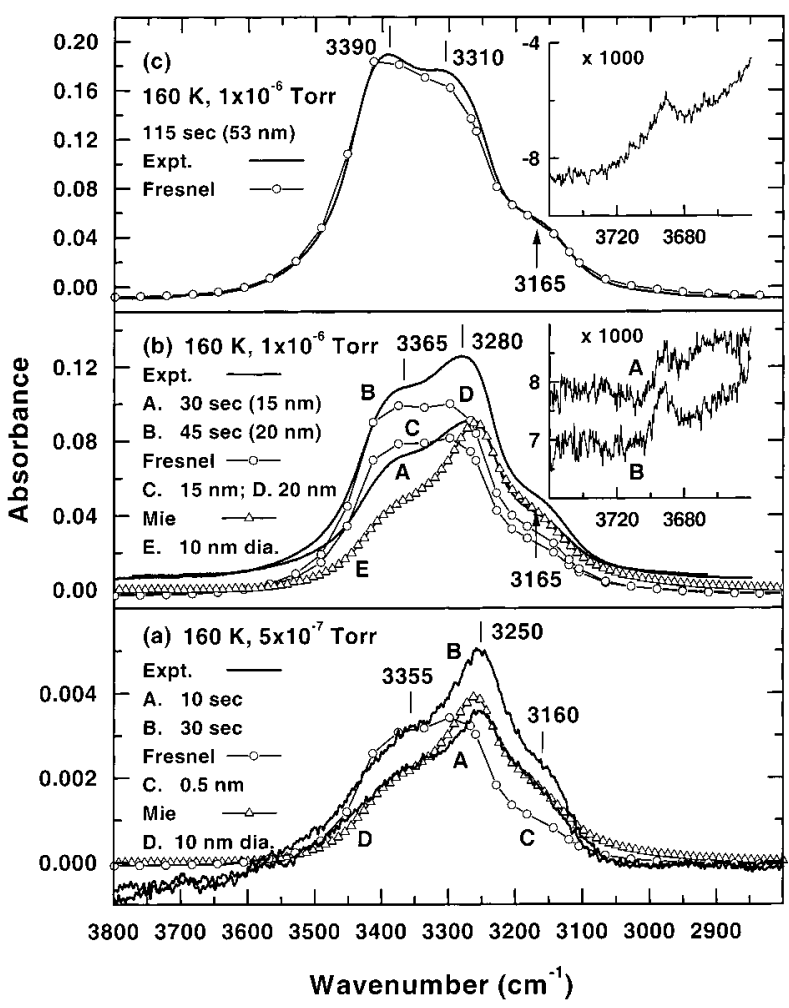

Figure 4. Comparison of experimental IR-RA spectra of the $\mathrm{OH}$ stretch region obtained at $160 \mathrm{~K}$ for the early stage of formation of a polycrystalline ice (pc-ice) film with Fresnel and Mie simulations. (a) Experimental spectra (at $2 \mathrm{~cm}^{-1}$ resolution) for an ice film obtained by vapor deposition at $5 \times 10^{-7}$ Torr for (A) 10 and (B) $30 \mathrm{~s}$ are compared with (C) the Fresnel spectrum of a 0.5-nm-thick pc-ice film (using optical constants obtained for films deposited at $163 \mathrm{~K}^{36}$ ), and (D) Mie spectrum for Ih ice (using optical constants obtained for films deposited at $210 \mathrm{~K}^{46}$ ) involving scattering spheres of $10 \mathrm{~nm}$ diameter. (b) Experimental spectra (at $2 \mathrm{~cm}^{-1}$ resolution) for an ice film obtained by vapor deposition at $1 \times 10^{-6}$ Torr for (A) 30 and (B) $45 \mathrm{~s}$ (corresponding to estimated thicknesses of 15 and $20 \mathrm{~nm}$, respectively) are compared with the Fresnel spectrum of pc-ice with film thicknesses of (C) 15 and (D) $20 \mathrm{~nm}$ and with (E) Mie spectrum for Ih ice involving scattering spheres of $10 \mathrm{~nm}$ diameter. (c) Experimental spectra (at 0.5 $\mathrm{cm}^{-1}$ resolutions) for an ice film obtained by vapor deposition at $1 \times$ $10^{-6}$ Torr for $115 \mathrm{~s}$ (corresponding to an estimated film thickness of $53 \mathrm{~nm}$ ) is compared with the Fresnel spectrum of a pc-ice film of the same thickness. Inserts in (b) and (c) show expanded views (with the ordinate expanded by 1000) of the $\mathrm{OH}$ dangling bond region (3760$3640 \mathrm{~cm}^{-1}$ ) for the respective films.

Continued deposition would result in the emergence of a polycrystalline film with RA spectra corresponding to intermediate between the Mie and Fresnel spectra (Figure 4b) and ultimately to the Fresnel spectra (Figure 4c). In particular, Figure $4 \mathrm{~b}$ and $4 \mathrm{c}$ shows the experimental RA spectra for water deposition at $1 \times 10^{-6}$ Torr with the substrate held at $160 \mathrm{~K}$ corresponding approximately to 30 and 45 , and $115 \mathrm{~s}$, respectively, into the phase formation. Fresnel spectra are generated with the appropriate film thicknesses that closest approximate the respective experimental spectra. For the 30- and 45-s deposition, the Mie spectra tend to give better agreement for the lower frequency part of the $\mathrm{OH}$ stretch, whereas the Fresnel spectra appear to better model the higher frequency part (Figure 4b). At the 115-s deposition, the experimental spectrum evolves into that best described by the Fresnel model (Figure 4c). The ice phase as depicted in Figure $4 \mathrm{~b}$ therefore corresponds to an intermediate state between the Fresnel thin-film and Mie particle-scatterer models. In this intermediate state, the accumulation of a sufficient amount of crystalline nuclei on the 


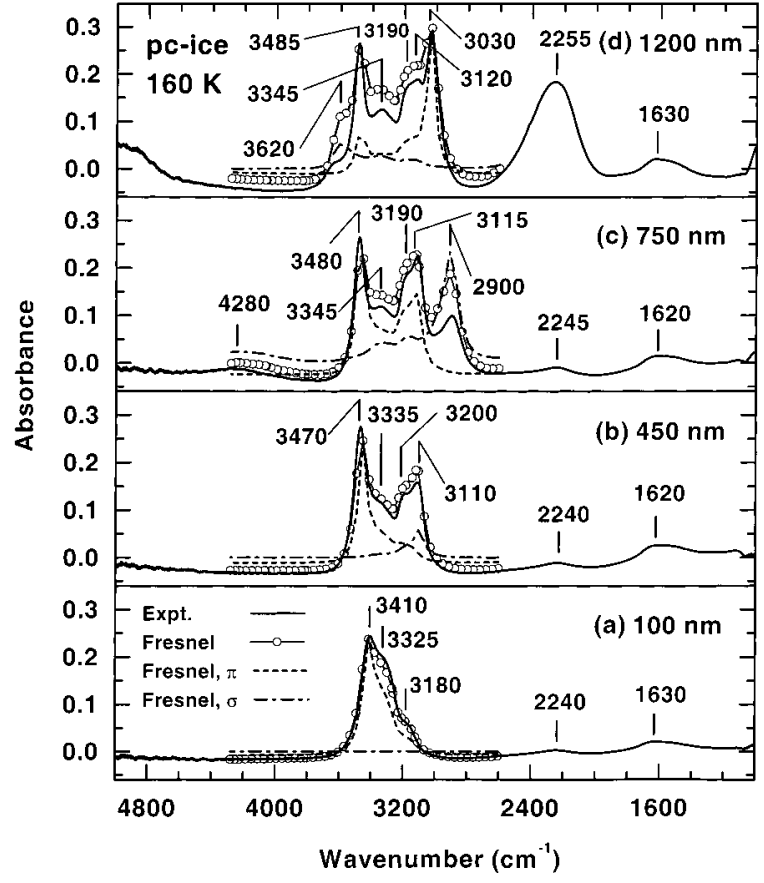

Figure 5. Comparison of experimental IR-RA spectra of polycrystalline ice (pc-ice) films obtained (at $0.5 \mathrm{~cm}^{-1}$ resolution) by vapor deposition at $160 \mathrm{~K}$ and $1 \times 10^{-6}$ Torr for (a) 3.5 , (b) 20 , (c) 33.5 , and (d) $52.5 \mathrm{~min}$ with the corresponding Fresnel spectra for nonpolarized light and their $\sigma$ - and $\pi$-polarized components (arbitrarily normalized) involving 100-, 450-, 750-, and 1200-nm-thick films, respectively.

substrate surface would eventually accelerate deposition in the inter-grain region. Figure $4 \mathrm{~b}$ and $4 \mathrm{c}$ (Inserts) also reveals the presence of a weak $\mathrm{OH} \mathrm{db}$ feature at $3693 \mathrm{~cm}^{-1}$ in the ice phase deposited at $160 \mathrm{~K}$, with the observed frequency corresponding to a 3-coordinated $\mathrm{OH}$ group. ${ }^{15}$ It is of interest to note that these $\mathrm{OH}$ db's exist even at the early stage of ice formation and presumably on the surfaces of the crystalline grains that give rise to the Mie spectra.

Further water deposition leads to the formation of a relatively thick film and a smooth vacuum-ice interface, and the corresponding spectra would be expected to be more similar to the Fresnel spectra. Figure 5 shows the experimental spectra for relatively thick films obtained by water vapor deposition at $1 \times 10^{-6}$ Torr with the substrate held at $160 \mathrm{~K}$ for 3.5 (Figure 5a), 20 (Figure 5b), 33.5 (Figure 5c), and 52.5 min (Figure 5d). In addition to the $\mathrm{OH}$ stretch features at 3410, 3325, and 3180 $\mathrm{cm}^{-1}$ shown in Figure 5a, the features near 1630 and $2240 \mathrm{~cm}^{-1}$ have been attributed to the $\mathrm{OH}$ bending band $\left(v_{2}\right)$ possibly coupled with the first overtone $\left(2 v_{\mathrm{R}}\right)$ of the hindered rotational lattice mode $\left(\nu_{\mathrm{R}} \approx 850 \mathrm{~cm}^{-137}\right)$ and to the combination band of the $\mathrm{OH}$ bending and hindered rotational mode and/or the second overtone $\left(3 v_{\mathrm{R}}\right)$ of the hindered rotational mode, respectively. ${ }^{37,48}$ With the exception of the feature at $2255 \mathrm{~cm}^{-1}$ for the 1200-nm-thick film, these two vibrational bands are found to be essentially stationary with a general increase in the spectral intensity with increasing film thickness (Figure 5). Furthermore, there is excellent agreement in the $\mathrm{OH}$ stretch region between the experimental spectrum and the corresponding Fresnel spectrum of a pc-ice film with a thickness of $100 \mathrm{~nm}$ (Figure 5a). Indeed, the good accord between the experiment and the Fresnel simulation for even thicker films allows the thickness parameter in the Fresnel calculation to be used as a semiempirical estimate of the thickness of the as-grown film. We have also performed optical interference measurements of the asgrown film and the film thickness so obtained is found to be in good accord with the corresponding Fresnel thickness parameter (depicted in Figure 5).

With increasing film thicknesses from $20 \mathrm{~nm}$ (Figure 4b) to $\sim 50 \mathrm{~nm}$ (Figure $4 \mathrm{c}$ ), the experimental band maximum is shifted to a higher frequency, with a concomitant increase in the intensity of the high-frequency shoulder near $3390-3400 \mathrm{~cm}^{-1}$. The absorbance of the $\mathrm{OH}$ stretch feature appears to level off at $\sim 70$ integrated AU's with increasing film thicknesses up to $100 \mathrm{~nm}$ (Figure 5a). Further film growth from 100 to $250 \mathrm{~nm}$ does not change the spectral intensity and band shape significantly. As the water deposition continues, the $\mathrm{OH}$ stretch region becomes considerably more complex, as depicted in Figure $5 \mathrm{~b}-$ $5 \mathrm{~d}$. In particular, at least three spectral features are evident near 3410,3325 , and $3180 \mathrm{~cm}^{-1}$ for the 100 -nm-thick pc-film (Figure $5 a)$, which originate from the three corresponding features at 3375,3300 , and 3180 , respectively, identified previously for the Fresnel spectrum of a 1-nm thick film (Figure 2). The shoulder feature at $3180 \mathrm{~cm}^{-1}$ for the $100-\mathrm{nm}$-thick film becomes a more prominent peak at $3200 \mathrm{~cm}^{-1}$ for the $450-\mathrm{nm}$ thick film, whereas the more intense features at 3325 and 3410 $\mathrm{cm}^{-1}$ shift to 3335 and $3470 \mathrm{~cm}^{-1}$, respectively (Figure $5 \mathrm{~b}$ ). These three observed features remain relatively "stationary" in frequencies with increasing film thickness above $450 \mathrm{~nm}$ (Figure $5 c-5 d)$.

To investigate the evolution of the remaining $\mathrm{OH}$ features in Figure 5 with increasing film thickness, we have evaluated the $\sigma$ - and $\pi$-components of the Fresnel spectra, which are arbitrarily normalized to the corresponding maxima of the overall calculated spectra. It is important to note that the absorbance of the overall Fresnel spectrum of an ice film, as defined by eq 1 , is not a simple linear combination of their constituent $\sigma$ - and $\pi$-components. The present discussion is therefore limited to the identification of the contributing features of individual $\sigma$ and $\pi$-components to the overall spectrum by their respective peak locations. Evidently, the frequency position, shape, and intensity of the $\mathrm{OH}$ stretch are determined almost entirely by the $\pi$-polarized component of the IR light for films with thicknesses below $\sim 250 \mathrm{~nm}$ (Figure 5a), where the contribution of the $\sigma$-component is seen to be negligible. Similar results have also been reported for very thin films, with thickness below $\sim 10 \mathrm{~nm}$, in earlier theoretical studies by Greenler ${ }^{31}$ and McIntyre and Aspens. ${ }^{33}$ For film thicknesses above $250 \mathrm{~nm}$, there is a general increase in the overall intensity of the $\sigma$-polarized profile. The low-frequency shoulder in the $\sigma$-polarized profile is seen to travel from $3110 \mathrm{~cm}^{-1}$ (for the $450-\mathrm{nm}$ thick film in Figure 5b) to $2900 \mathrm{~cm}^{-1}$ (for the 750 -nm-thick film in Figure 5c), which contributes to the corresponding feature at $3110 \mathrm{~cm}^{-1}$ and at $2900 \mathrm{~cm}^{-1}$ in the respective experimental spectra. Further increase in the film thickness to $1200 \mathrm{~nm}$ causes this $\sigma$-polarized feature to move further toward the lower frequency, giving rise to the strong enhancement to the spectral intensity of the feature observed at $2255 \mathrm{~cm}^{-1}$ (Figure 5d). As illustrated in Figure 3, this phenomenon is evidently caused by destructive interference of the $\sigma$-polarized IR light in a uniform film. Furthermore, a second $\sigma$-polarized feature near $4280 \mathrm{~cm}^{-1}$ appearing in the spectrum for the 750 $\mathrm{nm}$-thick film (Figure 5c) is also found to migrate to $3620 \mathrm{~cm}^{-1}$ for the 1200-nm-thick film (Figure 5d). This migration of interference peaks is believed to be responsible for the intensity enhancement of the $\mathrm{OH} \mathrm{db}\left(\right.$ at $3693 \mathrm{~cm}^{-1}$ ) for the film thickness between 850 and $1200 \mathrm{~nm}$ (see section 4.3 below). Similar interference peak movement is also evident for the $\pi$-polarized feature at $3115 \mathrm{~cm}^{-1}$ for the 750 -nm-thick film (Figure 5c), which travels to $3030 \mathrm{~cm}^{-1}$ as the film thickness is increased 
to $1200 \mathrm{~nm}$ (Figure 5d). The observation of destructive interference peak movements generally reflects the quality of film uniformity obtainable for pc-ice by vapor deposition.

In the case of grazing-angle incidence, there is an opportunity to qualitatively categorize three different regions of thickness according to the spectral behavior of the $\mathrm{OH}$ stretch mode. The extent of each region is a function of the incident angle and is therefore relative in value. In our case of $83^{\circ}$ angle of incidence, the $\mathrm{OH}$ stretch band intensity is proportional to the film thickness in the first thickness region of approximately below $50 \mathrm{~nm}$, and the shape of the band reflects the absorbance profile without being affected by the frequency profile of the vacuumice reflectance. In the intermediate thickness region of 50-250 $\mathrm{nm}$, the intensity of the $\mathrm{OH}$ stretch is saturated, in this case, at 70 integrated AU's (this limit depends on the incident angle) and remains unchanged despite further increase in the film thickness. Instead, a gradual blue shift in the maximum of the $\mathrm{OH}$ band toward the high-frequency minimum of the vacuumice reflection curve in the region of the $\mathrm{OH}$ stretch resonance (the so-called Christiansen effect ${ }^{49}$ ) is observed. The $\mathrm{OH}$ stretch band and the entire spectrum in the first two regions of film thickness can be principally described by the interaction of the $\pi$-polarized component of the IR light with the film. In the third thickness region starting at $\sim 300 \mathrm{~nm}$, the optical behavior of the $\mathrm{OH}$ stretch band with increasing film thickness is determined primarily by the reflectance of the incoming IR light from the vacuum-ice interface, because the refracted beam is completely absorbed by the ice in the frequency range of the $\mathrm{OH}$ stretch band. The splitting of the $\mathrm{OH}$ stretch observed in Figure $5 \mathrm{~b}-$ $5 \mathrm{~d}$ takes place due to the reflective character of the $\mathrm{OH}$ band. Unlike thinner films, the RA spectrum in this third region of thickness is the result of contributions from both $\pi$ - and $\sigma$-polarized components.

Although we have presented glancing-incidence FTIR-RAS data for ice films deposited at $160 \mathrm{~K}$, similar data have also been obtained for ice films deposited at temperature as low as $155 \mathrm{~K}$ and as high as $185 \mathrm{~K}$. These films have been classified as pc-ice based on similar Fresnel simulations discussed above. Our present data for pc-ice are found to be in good accord with the RA spectra for films deposited at $165 \mathrm{~K}$ over the $100-$ $1000-\mathrm{nm}$ thickness range reported by Zondlo et al. ${ }^{29}$ Our spectrum for a 20-nm-thick pc-ice film (Figure 4b) is also similar to that observed by Horn et al. for a pc-ice film obtained by crystallization at $155 \mathrm{~K}$ of an amorphous film grown at $80 \mathrm{~K} .{ }^{35}$ Figure 6a compares our spectrum for a 70-nm-thick pc-ice film (obtained at $83^{\circ}$ incidence) with the RA spectrum obtained at $75^{\circ}$ incidence by Jenniskens et al. ${ }^{7}$ for an ice film deposited at $80 \mathrm{~K}$ followed by annealing at $160 \mathrm{~K}$ for $175 \mathrm{~s}$. The spectrum by Jenniskens et al. is found to be in good agreement with a Fresnel spectrum calculated for an 80-nm-thick pc-ice film at $75^{\circ}$ incidence and is consistent with the present work. Furthermore, Barone et al. has reported a RA spectrum for an ice film deposited at $140 \mathrm{~K}$ followed by annealing to $160 \mathrm{~K}$, which is found to be in good agreement with our present data, and further attributed the observed dramatic change in the RA spectrum after annealing above $150 \mathrm{~K}$ to ordering of the amorphous ice to a more crystalline lattice. ${ }^{50}$ The good agreement of our spectra with the spectra reported in these early studies ${ }^{7,29,35,50}$ therefore confirms the polycrystalline character of the ice films prepared by direct vapor deposition at temperature above $155 \mathrm{~K}$.

4.2 Noncrystalline Ice Deposition at 128-145 K. Figure 7a compares the FTIR-RA spectrum of the initial stage of ncice phase formation, which corresponds approximately to $30 \mathrm{~s}$ of water deposition at $5 \times 10^{-8}$ Torr with the $\mathrm{Cu}$ substrate held

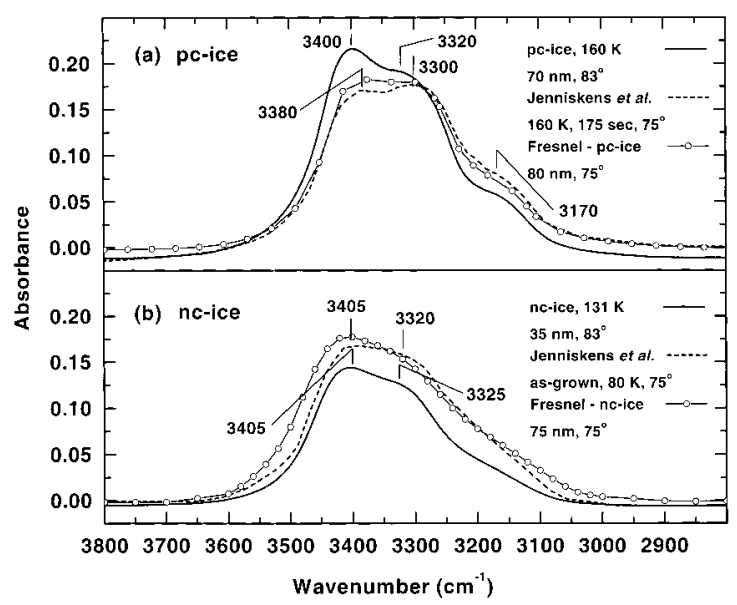

Figure 6. Comparison of experimental IR-RA spectra obtained at $83^{\circ}$ incidence for (a) a 70-nm-thick polycrystalline ice (pc-ice) film deposited at $160 \mathrm{~K}$ (recorded at $0.5 \mathrm{~cm}^{-1}$ resolution) and (b) a $35-\mathrm{nm}$ thick noncrystalline ice (nc-ice) film deposited at $131 \mathrm{~K}$ (recorded at $2 \mathrm{~cm}^{-1}$ resolution) with the corresponding RA spectra reported by Jenniskens et al. ${ }^{7}$ at $75^{\circ}$ incidence for ice films deposited at $80 \mathrm{~K}$ followed by annealing at $160 \mathrm{~K}$ for $175 \mathrm{~s}$, and as-grown at $80 \mathrm{~K}$, respectively. The latter spectra are also compared with the respective Fresnel spectra for an 80-nm-thick pc-ice film and a 75-nm-thick ncice film calculated at $75^{\circ}$ incidences.

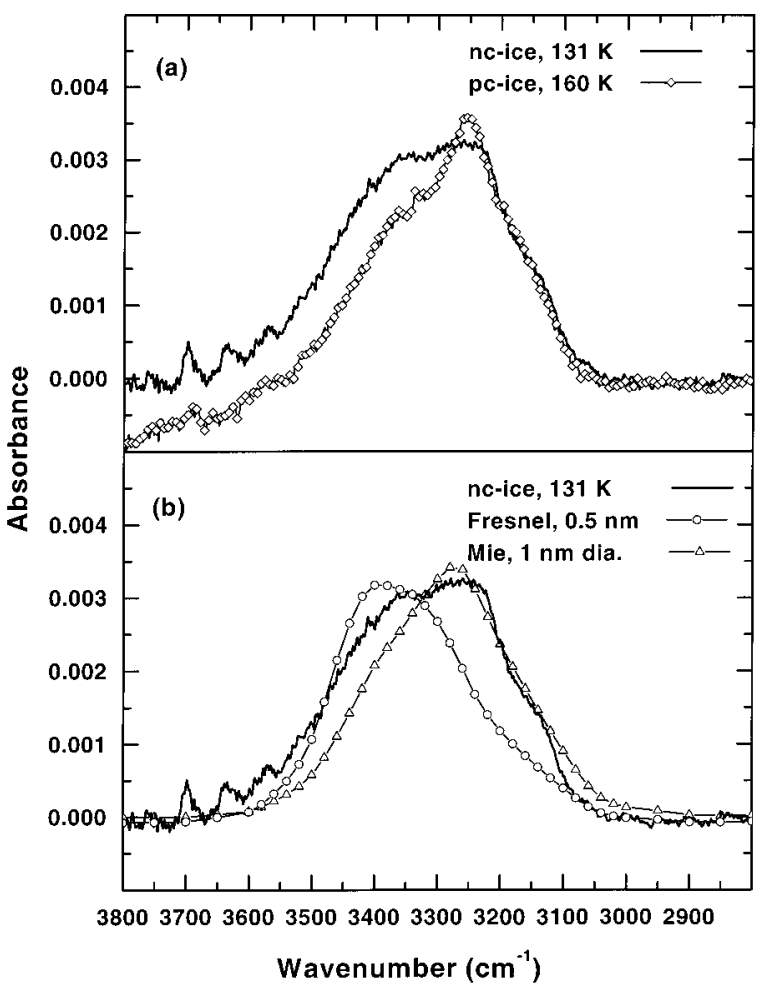

Figure 7. Comparison of experimental IR-RA spectrum (at $2 \mathrm{~cm}^{-1}$ resolution) for a noncrystalline ice (nc-ice) film obtained by vapor deposition at $131 \mathrm{~K}$ and $5 \times 10^{-8}$ Torr for $30 \mathrm{~s}$ with (a) that for a polycrystalline ice (pc-ice) film obtained by vapor deposition at $160 \mathrm{~K}$ and $5 \times 10^{-7}$ Torr for $10 \mathrm{~s}$, and (b) Fresnel spectrum for a 0.5-nmthick nc-ice film and Mie spectrum involving scattering spheres of 1 nm diameter.

at $131 \mathrm{~K}$, with that of the initial stage of pc-ice formation depicted in Figure 4a, curve A. With a more intense highfrequency shoulder, the $\mathrm{OH}$ stretch band for the nc-ice deposit is noticeably wider than its corresponding pc-ice analogue. As shown in Figure 7b, the Mie spectrum (obtained with a scatterer size of $1 \mathrm{~nm}$ diameter) approximates well the lower-frequency half of the $\mathrm{OH}$ stretch band, whereas the Fresnel spectrum 


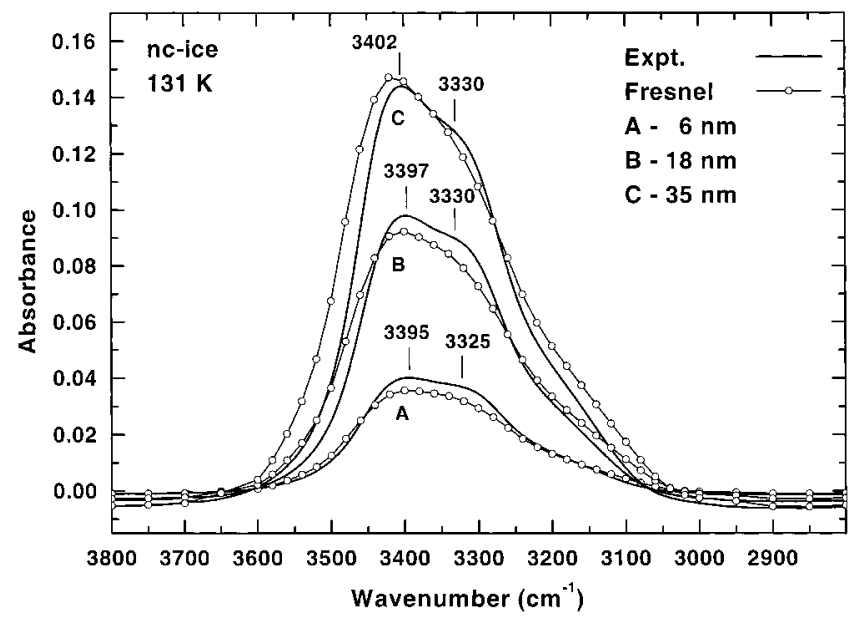

Figure 8. Comparison of experimental IR-RA spectra (at $2 \mathrm{~cm}^{-1}$ resolution) for noncrystalline ice (nc-ice) films deposited at $131 \mathrm{~K}$ and $1 \times 10^{-6}$ Torr for (A) 40, (B) 65, and (C) $90 \mathrm{~s}$ with the corresponding Fresnel spectra for film thicknesses of 6,18 , and $35 \mathrm{~nm}$, respectively.

obtained for a 0.5 -nm-thick nc-ice film fits the higher-frequency part better. The lack of complete agreement over the entire band for both Mie and Fresnel simulations suggests that the initial stage of nc-ice formation is best described as an intermediate between the Mie and Fresnel models that involves islands or aggregates of ice clusters. These very small water clusters are likely formed in the gas phase near the cold surface of the substrate. ${ }^{47}$

It should be noted that the optical constants of amorphous ice used to calculate the Mie and Fresnel spectra were measured for ice deposited at $77 \mathrm{~K},{ }^{38}$ which is lower than the temperature used in the present experiment $(131 \mathrm{~K})$. The difference in the deposition temperature could lead to the formation of different water networks that could exhibit an $\mathrm{OH}$ stretch band with different frequency positions and shape. In particular, Hagen et al. have shown that annealing an amorphous ice sample deposited at $10 \mathrm{~K}$ to $130 \mathrm{~K}$ leads to a red shift of the $\mathrm{OH}$ stretch in the transmittance IR spectrum, along with narrowing of the spectral line and an increase in the peak intensity. ${ }^{14}$ These irreversible spectral changes were attributed to structural reconstruction in the water network that occurs below the temperature of phase transformation to Ic (135-140 K) during the annealing process. ${ }^{14}$ In addition, reversible spectral changes in the $\mathrm{OH}$ feature involving red shift, band narrowing and enhanced peak intensity with decreasing sampling temperature were also observed, which therefore indicates that the optical constants of the nc-ice films also depend on the temperature of the film (at which measurement is made). The differences in both the deposition temperature and the sampling temperature of the ice film can therefore account for part of the observed differences between the experiment and the Mie and Fresnel spectra. Moreover, the $\mathrm{OH}$ stretch band in the Fresnel spectrum for the nc-ice film is blue-shifted and wider in comparison with that of the corresponding Fresnel spectrum for a pc-ice film (and with the experimental pc-ice spectrum), consistent with the aforementioned temperature behavior observed by Hagen et al. ${ }^{14}$ (See Figure 9 below).

Figure 8 compares the experimental spectra of thin nc-ice films deposited at $1 \times 10^{-6}$ Torr for 40,65 , and $90 \mathrm{~s}$ with the substrate held at $131 \mathrm{~K}$ with Fresnel spectra for nc-ice with corresponding film thicknesses of 6,18 , and $35 \mathrm{~nm}$, respectively. As expected with increasing film thickness in this range, the overall $\mathrm{OH}$ stretch band increases in intensity. The small blue shift in the peak maximum from $3395 \mathrm{~cm}^{-1}$ (Figure 8, curve

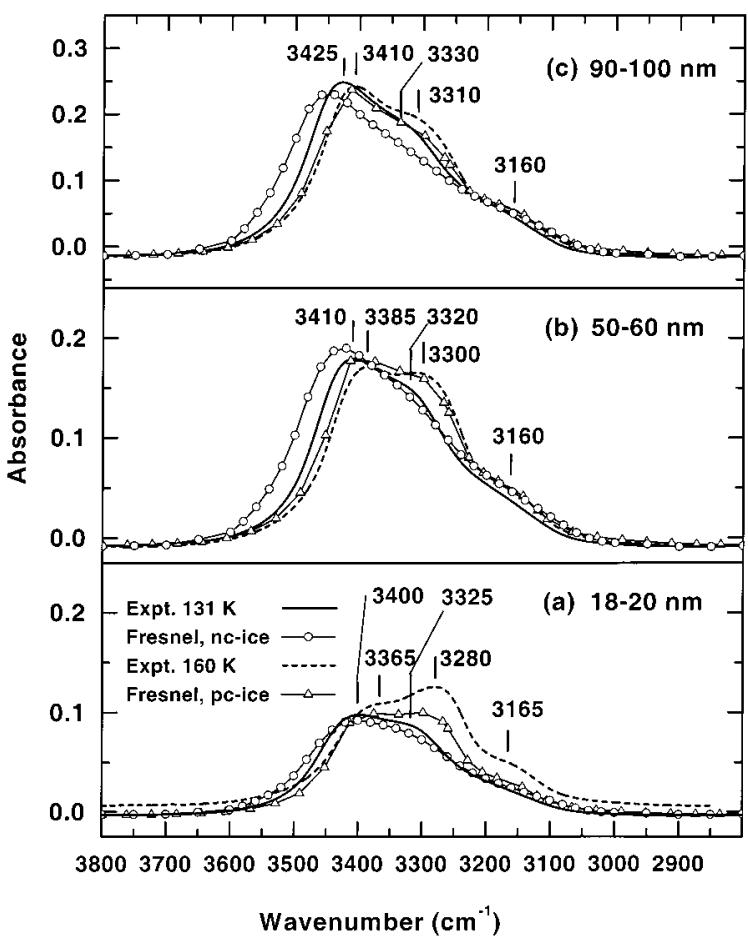

Figure 9. Comparison of experimental IR-RA spectra and the corresponding Fresnel spectra in the $\mathrm{OH}$ stretch region for noncrystalline ice (nc-ice) and polycrystalline ice (pc-ice) deposited at $1 \times 10^{-6}$ Torr and 131 and $160 \mathrm{~K}$, respectively, for films with different thicknesses. The corresponding thickness parameter used for the Fresnel simulations are (a) 18 (20) $\mathrm{nm}$ for $45 \mathrm{~s}$ of deposition for nc-ice (pc-ice), (b) 60 (50) $\mathrm{nm}$ for 120 (115) seconds of deposition for nc-ice (pc-ice), and (c) $90(100) \mathrm{nm}$ for 220 (240) seconds of deposition for nc-ice (pcice). The nominal spectral resolution is $2 \mathrm{~cm}^{-1}$ for nc-ice spectra and $0.5 \mathrm{~cm}^{-1}$ for pc-ice spectra.

A) to $3402 \mathrm{~cm}^{-1}$ (Figure 8 , curve C) along with a slight increase in the relative intensity of the high-frequency shoulder with increasing film thickness is due principally to the physical optical effects as illustrated in the Fresnel simulations and not to structural changes in the nc-ice network during film growth. The Fresnel spectra are evidently in reasonable agreement with the experiment for the nc-ice film in this thickness range, with notable discrepancies found in the width and the higherfrequency part of the band. In keeping with the observations by Hagen et al., ${ }^{14}$ these discrepancies could be attributed to the differences in the structures of the water network at different deposition temperatures. The stronger higher-frequency part of the Fresnel spectra obtained with optical constants at $77 \mathrm{~K}$ than the experimental spectra collected at $131 \mathrm{~K}$ suggests that stronger hydrogen bonding and more structural uniformity in the water network could be obtained at a higher deposition temperature.

Figure 9 compares the experimental and the corresponding Fresnel spectra of nc-ice and pc-ice films of three different thicknesses: $18-20 \mathrm{~nm}, 50-60 \mathrm{~nm}$, and $90-100 \mathrm{~nm}$. Like the nc-ice film of a smaller thickness (Figure 8), the FTIR-RA spectra of the thicker nc-ice films are also found to be in general accord with the corresponding Fresnel spectra. Unlike pc-ice, discrepancies are clearly notable in the shape and the higherfrequency part of the Fresnel spectra when compared with the experiment for nc-ice. For films with a larger thickness, there is an apparent blue shift in the $\mathrm{OH}$ stretch band maximum for nc-ice relative to that for pc-ice [e.g., $3410 \mathrm{~cm}^{-1}$ vs $3385 \mathrm{~cm}^{-1}$ for $50-60 \mathrm{~nm}$ (Figure 9b), and $3425 \mathrm{~cm}^{-1}$ vs $3410 \mathrm{~cm}^{-1}$ for 90-100 nm (Figure 9c)] and in the frequency position of the 


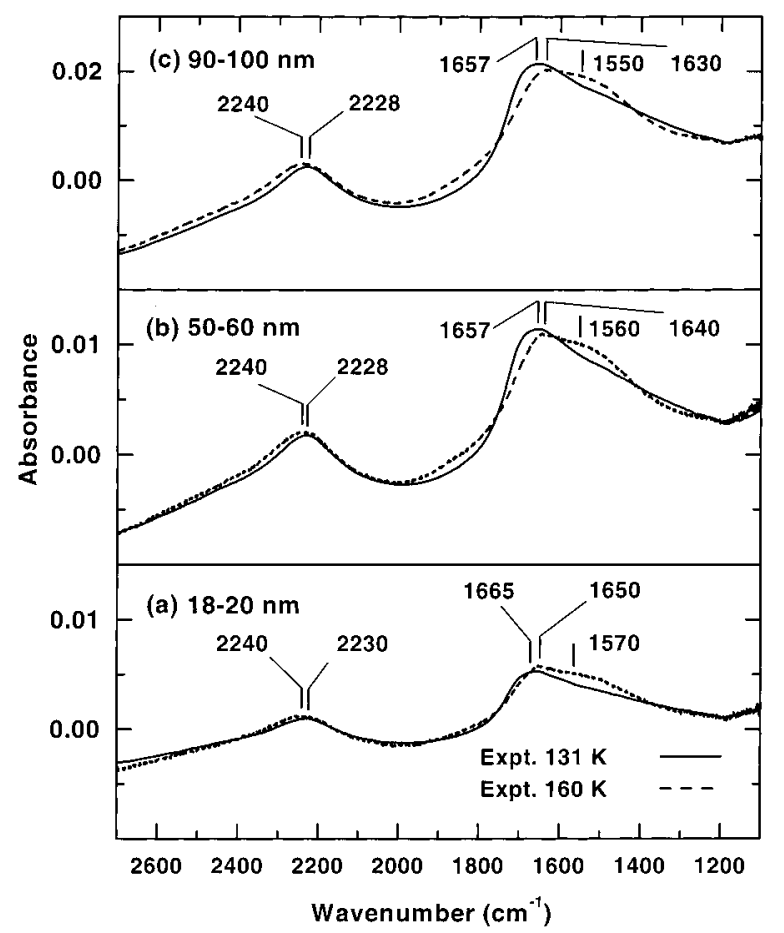

Figure 10. Comparison of experimental IR-RA spectra of the $\mathrm{OH}$ bending and combination band region for noncrystalline ice (nc-ice) and polycrystalline ice (pc-ice) deposited at $1 \times 10^{-6}$ Torr and 131 and $160 \mathrm{~K}$, respectively, for films with different thicknesses. The corresponding thickness parameter estimated in the Fresnel simulations of the $\mathrm{OH}$ stretch region (Figure 9) are (a) 18 (20) $\mathrm{nm}$ for $45 \mathrm{~s}$ of deposition for nc-ice (pc-ice), (b) 60 (50) nm for 120 (115) seconds of deposition for nc-ice (pc-ice), and (c) 90 (100) nm for 220 (240) seconds of deposition for nc-ice (pc-ice). The nominal spectral resolution is 2 $\mathrm{cm}^{-1}$ for nc-ice spectra and $0.5 \mathrm{~cm}^{-1}$ for pc-ice spectra.

band center of the $\mathrm{OH}$ stretch [e.g., $3320 \mathrm{~cm}^{-1}$ vs $3300 \mathrm{~cm}^{-1}$ for $50-60 \mathrm{~nm}$ (Figure 9b) and $3330 \mathrm{~cm}^{-1}$ vs $3310 \mathrm{~cm}^{-1}$ for 90-100 nm (Figure 9c)]. The low-frequency shoulder clearly observable at $3160-3165 \mathrm{~cm}^{-1}$ in the spectra of pc-ice is less prominent in the nc-ice spectra (Figure 9a). The blue shift and the less discernible shape of the entire $\mathrm{OH}$ stretching mode for nc-ice reflect the structural differences in the organization of the water networks between nc-ice and pc-ice, indicating the weaker hydrogen bonding system with a larger variation in such structural parameters as the nearest-neighbor separation and the $\mathrm{OH}-\mathrm{O}$ angle. In the case of the 18-20-nm-thick film, whereas the respective pc-ice spectrum clearly illustrates the Mie scattering effect due to the presence of crystalline scatterers (not shown), the corresponding spectrum for nc-ice can best be approximated by the Fresnel model (Figure 9a), which suggests that the structure of the nc-ice film is more homogeneous.

Figure 10 further demonstrates the spectral differences in the bending and combination bands between nc-ice and pc-ice for the same film thicknesses. In particular, the $\mathrm{OH}$ bending band for nc-ice spectra is blue shifted to $1665 \mathrm{~cm}^{-1}$ from $1650 \mathrm{~cm}^{-1}$ for pc-ice (Figure 10a) and appears to be narrower without the weak low-frequency shoulder at $1570-1550 \mathrm{~cm}^{-1}$ characteristic of pc-ice. The small but discernible red shift in the band maximum of the combination band of nc-ice $\left(2230 \mathrm{~cm}^{-1}\right)$ in comparison with that for the pc-ice $\left(2240 \mathrm{~cm}^{-1}\right.$, Figure $\left.10 \mathrm{a}\right)$ is in qualitative spectral agreement with the transmittance spectrum reported by Hardin and Harvey. ${ }^{37}$ These spectral differences are manifested more clearly with increasing film thickness (Figure 10b-10c). The difference in the frequency positions and relative intensities of the spectral features of the $\mathrm{OH}$ stretching and bending modes can therefore be used to identify

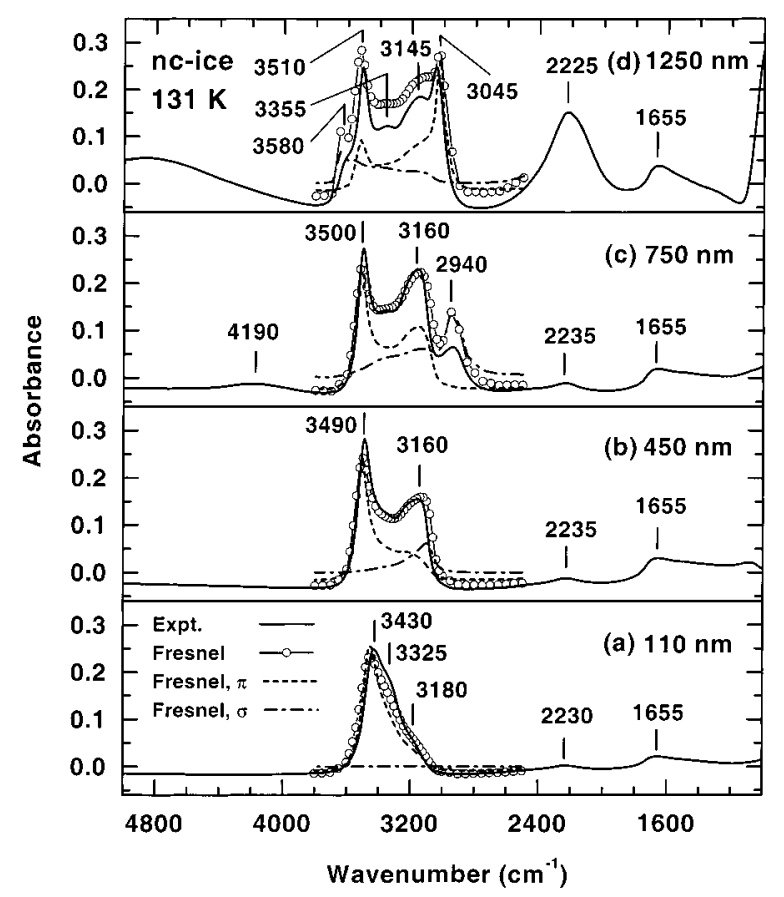

Figure 11. Comparison of experimental IR-RA spectra of noncrystalline ice (nc-ice) films obtained (at $0.5 \mathrm{~cm}^{-1}$ resolution) by vapor deposition at $131 \mathrm{~K}$ for (a) 3.5 , (b) 20.5 and (c) $33.5 \mathrm{~min}$ at $1 \times 10^{-6}$ Torr and (d) $11 \mathrm{~min}$ at $5 \times 10^{-6}$ Torr with the corresponding Fresnel spectra for nonpolarized light, and their $\sigma$ - and $\pi$-polarized components (arbitrarily normalized) involving 110-, 450-, 750-, and 1200-nm-thick films, respectively. Nominal spectral resolution is $2 \mathrm{~cm}^{-1}$ for spectra $(\mathrm{a}-\mathrm{c})$ and $0.5 \mathrm{~cm}^{-1}$ for spectrum (d).

the nature of the ice film deposited below $145 \mathrm{~K}$ as nc-ice. However, it is not a straightforward endeavor to determine the magnitude and nature of the structural differences between ncice and pc-ice based on FTIR-RAS data alone.

Figure 11 shows the experimental spectra for relatively thick films obtained by water vapor deposition at $1 \times 10^{-6}$ Torr for $3.5,20.5$, and $33.5 \mathrm{~min}$ and at $5 \times 10^{-6}$ Torr for $11 \mathrm{~min}$ with the substrate held at $131 \mathrm{~K}$, which correspond to nc-ice film thicknesses of $110,450,750$, and $1250 \mathrm{~nm}$, respectively, as estimated by the optical interference method. As before, the features near 1655 and $2230 \mathrm{~cm}^{-1}$ (Figure 11a) can be assigned, respectively, as the $\mathrm{OH}$ bending band and the combination band of the $\mathrm{OH}$ bending and hindered rotation modes; ${ }^{48}$ and these features remain essentially "stationary" in peak positions with increasing film thickness. The spectral evolution of the $\mathrm{OH}$ stretch (near $3430 \mathrm{~cm}^{-1}$ for the 110 -nm-thick film shown in Figure 11a) with growth of the nc-ice film is also similar to that observed for the pc-ice film growth (Figure 5). In particular, three relatively "stationary" features at 3490-3510 (band maximum), 3355, and $3160-3145 \mathrm{~cm}^{-1}$ can be resolved for film thickness greater than $450 \mathrm{~nm}$ (Figure 11b-11d). The band maximum for nc-ice is seen to shift to a higher frequency (Figures 9 and 11), and the integrated intensity of the absorption band becomes saturated at $\sim 70$ integrated AU at film thickness near $120 \mathrm{~nm}$, as observed similarly for pc-ice. We also show in Figure 11 the $\sigma-$ and $\pi$-polarized components arbitrarily normalized to the maximum of the overall Fresnel spectrum. For film thickness below $250 \mathrm{~nm}$, the shape of the $\mathrm{OH}$ stretch band is predominantly determined by reflection-absorption of the $\pi$-polarized component of the incident light (Figure 11a), with negligible contribution from the $\sigma$-polarized component. For film thickness greater than $250 \mathrm{~nm}$, the $\sigma$-polarized component generally strengthens with the emergence of an 


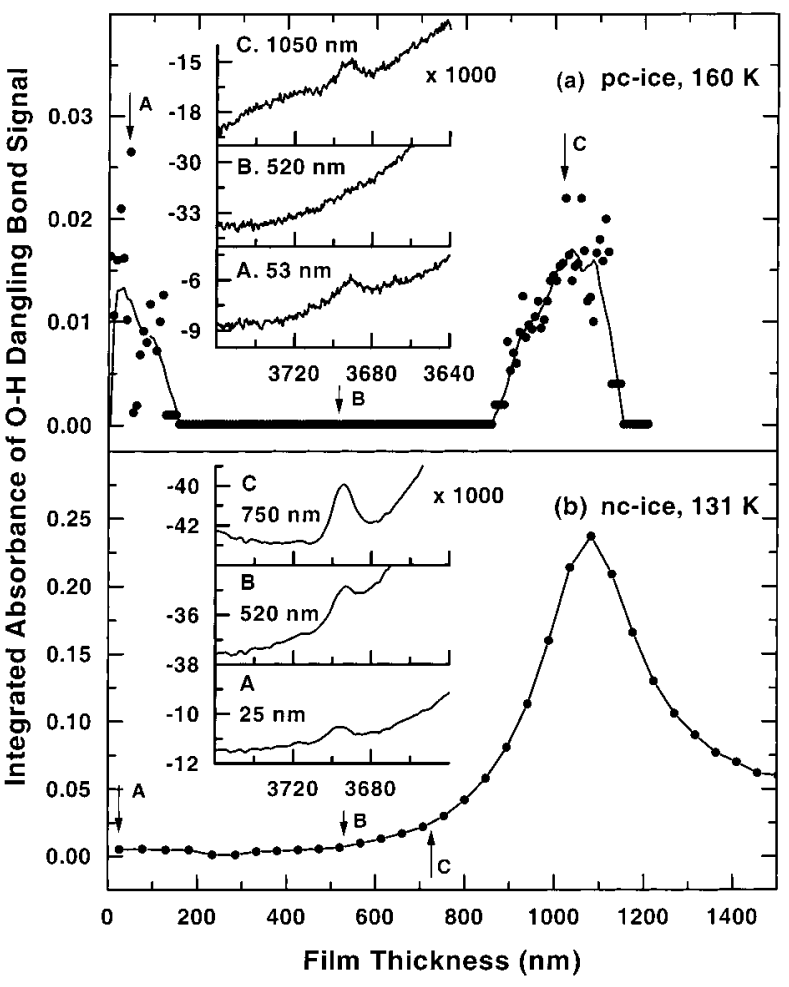

Figure 12. Integrated absorbance intensity of the $\mathrm{OH}$ dangling bond signal as a function of the film thickness for (a) polycrystalline ice (pc-ice) deposited at $160 \mathrm{~K}$ and $1 \times 10^{-6}$ Torr, and (b) noncrystalline ice (nc-ice) deposited at $131 \mathrm{~K}$ and $5 \times 10^{-6}$ Torr. The curves are used to guide the eyes only. The film thickness is estimated by optical interference method and is found to be in reasonable agreement with the thickness parameter used in the respective Fresnel simulations. Inserts (with the ordinate expanded by 1000) show the $\mathrm{OH}$ dangling bond feature at selected film thicknesses marked by arrows.

interference feature travelling from $\sim 3160 \mathrm{~cm}^{-1}$ at $450 \mathrm{~nm}$ (Figure 11b) to $2940 \mathrm{~cm}^{-1}$ at $750 \mathrm{~nm}$ (Figure 11c) and to 2225 $\mathrm{cm}^{-1}$ at $1250 \mathrm{~nm}$ (Figure 11d). Another $\sigma$-polarized interference feature near $4190 \mathrm{~cm}^{-1}$ for film thickness of $750 \mathrm{~nm}$ (Figure 11c) is also seen to travel to $3580 \mathrm{~cm}^{-1}$ for the 1250 -nm-thick film (Figure 11d). The passage of this second interference feature through the spectral window of the $\mathrm{OH} \mathrm{db}$ causes amplification of the $\mathrm{OH}$ db signal for nc-ice films with thickness of $800-1400 \mathrm{~nm}$ (as shown later in Figure 12). It is evident that the $\pi$-polarized components contribute prominently to the three aforementioned "stationary" $\mathrm{OH}$ stretch features over the film thickness range covered in Figure 11. The movement of the main $\pi$-polarized feature (near $3430 \mathrm{~cm}^{-1}$ for the $110-\mathrm{nm}$ thick film in Figure 11a) to a higher frequency with increasing film thickness gives rise to the observed blue shift of the band maximum. As noted earlier, this shift is related to the physics of reflection-absorption and not to possible structural changes in the nc-ice network with an increase in the film thickness. For thicker films, the $\pi$-polarized interference feature observed at $\sim 3160 \mathrm{~cm}^{-1}$ for the 750 -nm-thick film (Figure 11c) is also found to travel to a lower frequency with increasing film thickness, e.g. $3045 \mathrm{~cm}^{-1}$ for the 1250-nm-thick film (Figure 11d). The evolution of the underlying $\sigma$ - and $\pi$-polarized Fresnel contributions to the overall spectrum of nc-ice with increasing film thickness (Figure 11) is therefore similar to that found for pc-ice (Figure 5).

It is important to note that we have also performed FTIRRAS experiments on ice grown at a different temperature between 128 and $145 \mathrm{~K}$. Similar spectral results have been obtained, therefore suggesting that the ice films obtained by vapor deposition over $128-145 \mathrm{~K}$ can be characterized as ncice as discussed above.

There have been numerous earlier studies exploring the nature of nc-ice and pc-ice. In particular, as it was shown by an earlier study of thermal evolution of the hyperquenched water droplets by using X-ray diffraction and differential calorimetry, an ice phase predominantly in the form of vitreous ice could be obtained at deposition temperature below $140 \mathrm{~K} .{ }^{6}$ It should be noted that the temperatures for glass-to-liquid transition and for crystallization to Ic are found to be $129-143 \mathrm{~K}$ and $165 \mathrm{~K}$, respectively. ${ }^{6,51}$ The temperature of crystallization of amorphous ice to Ic is generally a function of the deposition temperature and postdeposition history of the amorphous sample, which reflects the complex heterogeneous nature of amorphous ice. ${ }^{52}$ Furthermore, the thermal evolution data for hyperquenched solid water prepared at $130-150 \mathrm{~K}^{6}$ suggests the formation of a mixture of cubic ice and glassy materials. Hyperquenching above $160 \mathrm{~K}$ was found to produce predominantly cubic ice with at most $20 \%$ amorphous component, ${ }^{6}$ which could persist up to the Ic-to-Ih phase transition temperature $(230 \mathrm{~K})$. Partly on the basis of the time evolution of FTIR-RA spectra of thin ice films (vapor-deposited at $80 \mathrm{~K}$ with an estimated thickness of $\sim 20 \mathrm{~nm}$ ) postannealed to $160 \mathrm{~K}$, Jenniskens et al. ${ }^{7}$ concluded that the amorphous ice so obtained, when annealed to above the glass-to-liquid transition temperature, becomes a "viscous" liquid that coexists with Ic in the temperature range 140-210 $\mathrm{K}$.

In the present work, crystallization of nc-ice deposited at 131 $\mathrm{K}$ is found to occur upon annealing to temperature starting from $\sim 160 \mathrm{~K}$. The spectra of the samples deposited at $131 \mathrm{~K}$ followed by annealing to $165 \mathrm{~K}$ (not shown) are found to be essentially identical to the spectra of pc-ice prepared by direct deposition at $160 \mathrm{~K}$. In light of these results, we may interpret the character of pc-ice deposited at $160 \mathrm{~K}$ in our experiment (Figures 4 and 5) as predominantly cubic ice. Although the deposition temperature for pc-ice used in the present experiment is well below the Ic-to-Ih transition temperature $(230 \mathrm{~K})$, our FTIR-RAS data does not exclude the possible presence of hexagonal ice because of the nearly identical optical properties of the Ic and Ih phases. On the basis of the analysis of the $\mathrm{OH}$ stretch, our data does not reveal any spectral evidence for the presence of nc-ice for films deposited above $155 \mathrm{~K}$. However, the presence of noncrystalline material in, e.g., the inter-grain regions of pcice or the surface region of the film cannot be ruled out due particularly to the weaker absorption of nc-ice relative to pcice. For ice deposited below $145 \mathrm{~K}$, we have not found any spectral evidence of the existence of polycrystalline fragments, based on the shapes and frequency positions of the $\mathrm{OH}$ stretching and bending modes. The nc-ice obtained at $131 \mathrm{~K}$ (Figure 11) could therefore be attributed predominantly to amorphous solid.

Figure $6 \mathrm{~b}$ compares our experimental spectrum recorded at $83^{\circ}$ incidence for nc-ice deposited at $131 \mathrm{~K}$ with that collected at $75^{\circ}$ incidence for nc-ice obtained at $80 \mathrm{~K}$ by Jenniskens et al. ${ }^{7}$ The latter spectrum was found to be in good accord with the Fresnel spectrum for a 75-nm-thick nc-ice film calculated at $75^{\circ}$ incidence using the optical constants of amorphous ice at $77 \mathrm{~K}$ reported by Leger et al. ${ }^{38}$ Apart from the differences in the intensity caused by the different angles of incidence, our spectrum obtained at $131 \mathrm{~K}$ is similar that of the amorphous ice obtained at $80 \mathrm{~K}$ by Jenniskens et al., ${ }^{7}$ suggesting that the nature of nc-ice obtained in the present work could be interpreted as amorphous solid. Furthermore, Jenniskens et al. observed no discernible spectral changes upon annealing the sample to 
$145 \mathrm{~K}$ and attributed the subsequent changes observed upon further annealing to $155 \mathrm{~K}$ to crystallization of amorphous ice to cubic ice, which was confirmed for thin ice films by electron diffraction. ${ }^{7}$ This observation is also in qualitative agreement with the temperature range $(128-145 \mathrm{~K})$ over which we obtain the nc-ice films. However, in contrast to the time evolution of the $\mathrm{OH}$ band observed for the film postannealed at $160 \mathrm{~K}$ by Jenniskens et al., ${ }^{7}$ we do not observe any such similar behavior for ice films grown in the present work and therefore cannot confirm the presence of viscous liquid as previously suggested. ${ }^{7}$ Furthermore, the $\mathrm{OH} \mathrm{db}$ signal at $3692 \mathrm{~cm}^{-1}$ detected on the as-grown amorphous ice at $80 \mathrm{~K}$ was found to disappear after postannealing the ice film to $160 \mathrm{~K}$ by Jenniskens et al. ${ }^{7} \mathrm{By}$ contrast, the $\mathrm{OH} \mathrm{db}$ signal on nc-ice grown at $131 \mathrm{~K}$ in the present work (spectra not shown) is found to persist up to 160$165 \mathrm{~K}$, during which crystallization occurs.

4.3 OH Dangling Bonds. The $\mathrm{OH}$ db signal can be detected for ice films deposited over a wide range of temperature, from $128 \mathrm{~K}$ in the case of nc-ice to as high as $185 \mathrm{~K}$ for pc-ice film, which indicates the remarkable thermal stability of the elements of ice surface containing these $\mathrm{OH}$ dangling groups. The spectral intensity of the $\mathrm{OH} \mathrm{db}$ feature observed at $3700-3690 \mathrm{~cm}^{-1} 15$ as a function of film thickness for pc-ice (obtained at $160 \mathrm{~K}$ ) and nc-ice (obtained at $131 \mathrm{~K}$ ) is shown in Figure 12. Given that the $\mathrm{OH} \mathrm{db}$ feature is generally very weak relative to the $\mathrm{OH}$ stretch feature and could therefore be susceptible to spectral noise and baseline instability at these frequencies, only the general trend in the dependence of the $\mathrm{OH} \mathrm{db}$ signal on the film thickness can be inferred. According to the metal surface selection rule, only the $\mathrm{OH}$ db's that have a dipole moment component perpendicular to the metal surface could contribute to the RA signal in the case of a thin ice film (below $200 \mathrm{~nm}$ ), as shown in Figure 3d. The observation of the $\mathrm{OH}$ db RA signal on thin nc-ice films by Zondlo et al. ${ }^{29}$ shows that the $\mathrm{OH} \mathrm{db}$ band could be detected only with the $\pi$-polarized light. A significant amount of the $\mathrm{OH}$ db's that have dipole moments oriented parallel to the metal surface would remain invisible at this thickness range (below $<200 \mathrm{~nm}$ ) to the IR-RAS technique. With the exceptions of complete randomization of the $\mathrm{OH} \mathrm{db}$ orientation and of a fixed angular geometry for all $\mathrm{db}$ 's, the observed RA signal is not necessarily proportional to the amount of $\mathrm{OH} d b$ 's in the ice film.

For film thickness smaller than $\sim 200 \mathrm{~nm}$, the $\mathrm{OH}$ db signals for both pc-ice and nc-ice are found to be relatively weak and essentially independent of the film thickness (given the large uncertainty). The spectral intensity of the $\mathrm{OH} \mathrm{db}$ appears to diminish in the $150-850 \mathrm{~nm}$ thickness range for pc-ice but remains relatively constant up to a film thickness of $600 \mathrm{~nm}$ for nc-ice. For the 850-1200-nm-thick pc-ice and nc-ice films (Figure 12), the passage of the $\sigma$-polarized interference pattern over the optical window $3710-3680 \mathrm{~cm}^{-1}$ appears to significantly enhance the $\mathrm{OH}$ db signal (by over 20 -folds), which is in a good qualitative accord with the spectral simulation shown in Figure 3. This strong optical amplification in the observed signal does not necessarily correspond to the increase in the total amount of the $\mathrm{OH} d b$ 's in the material. The same phenomenon has also been observed for other absorption bands, most notably the combination band at $2255 \mathrm{~cm}^{-1}$ (Figure 5d) [2225 $\mathrm{cm}^{-1}$ (Figure 11d)], which is again in good accord with the simulation shown in Figure 3. Apparently, the amplification is much stronger in the case of nc-ice (Figure 12b) than pc-ice (Figure 12a). Because the amplification is related to the passage of the $\sigma$-polarized interference pattern, the experimental observation of such an optical effect shows that the dipole moments of the $\mathrm{OH}$ db's have surface-parallel components. For pc-ice films (Figure 12a), essentially the same magnitude of the $\mathrm{OH}$ $\mathrm{db}$ signal for the 850-1150-nm-thick film as that for a thin film $(<200 \mathrm{~nm})$ is observed. The lack of $\mathrm{OH}$ db signal in the intervening thickness region therefore does not necessarily indicate the absence of the $\mathrm{OH} \mathrm{db}$, but rather spectral interference that overwhelms the $\mathrm{OH} \mathrm{db}$ feature. This observation suggests that the total amount of the $\mathrm{OH} \mathrm{db}$ remains essentially the same with film growth, and the $\mathrm{OH}$ db dipole moments are oriented more or less randomly with the respect to the metal surface. Accordingly, we attribute the spectral signal at $\sim 3693$ $\mathrm{cm}^{-1}$ to $\mathrm{OH} \mathrm{db}$ groups on the external surfaces of the crystalline grains in the early stage of pc-ice deposition (with film thickness below $50 \mathrm{~nm}$ ), while for thicker films these $\mathrm{OH}$ db's are thought to be located on the external surface of the pc-ice film itself. The $\mathrm{OH}$ db's that exist on the outer surfaces of crystalline grains in the initial stage of pc-ice film formation would be effectively saturated by water molecules that fill the interstitial space during the film deposition process. Although the local nature of the water network in the inter-grain regions remains controversial, the present results suggest a near-crystalline structure for these regions in the water network.

The behavior of the $\mathrm{OH}$ db signal is different in the case of nc-ice films. In particular, the intensity of the signal for nc-ice films thicker than $1400 \mathrm{~nm}$ is still significantly higher than that for thin films $(<150-200 \mathrm{~nm})$, unlike pc-ice films. This difference suggests that the total amount of $\mathrm{OH} \mathrm{db}$ in nc-ice may in fact increase with film growth, which is in general accord with the observation made by Zondlo et al. that the total amount of $\mathrm{OH}$ db's in low-density ice (obtained at $94 \mathrm{~K}$ ) increases with increasing film thickness. ${ }^{29}$ To account for the proportionality of the abundance of the $\mathrm{OH}$ db's with respect to the amount of ice, the latter work further concluded that the $\mathrm{OH} d b$ 's are located on the surfaces of multiple micropores inside the amorphous solid ice network. ${ }^{29}$ The existence of the $\mathrm{OH}$ db's on the internal surfaces of open and close micropores has also been predicted for film growth of low-density ice under appropriate conditions by Zhdanov and Norton using Monte Carlo simulation. ${ }^{26}$ The observed thickness profile of the $\mathrm{OH}$ $\mathrm{db}$ signal shown in Figure $12 \mathrm{~b}$ is similar to the simulated profile in Figure 3d, which confirms the increase in the total amount of $\mathrm{OH}$ db's with increasing film thickness and the essentially random orientation of the $\mathrm{OH}$ db's. The large difference in the deposition temperature between our experiment and that of Zondlo et al. is expected to cause some difference in the organization of the noncrystalline network that might result in a smaller amount of the internal micropores in the case of the higher-temperature deposit. The temperature dependence of the amount of micropores in nc-ice has been explained earlier by an increase in the surface mobility of incoming molecules with increasing temperature. ${ }^{29}$ We conclude therefore that the $\mathrm{OH}$ $\mathrm{db}$ 's are likely located on the highly convoluted external surface of the nc-ice film, which is in general accord with the studies by Callen et al. ${ }^{27}$ Rowland and Devlin, ${ }^{15}$ Horn et al.,${ }^{28}$ and Zondlo et al. ${ }^{29}$ We further suggest that the nc-ice vapordeposited at $128 \mathrm{~K}$ or higher temperature may have a "tracery" organization at least in the near-surface region that could give rise to the $\mathrm{OH} \mathrm{db}$ signal. In the case of thin nc-ice film, the $\mathrm{OH}$ db's are most likely located on the external surface of the film, whereas with the increase in the film thickness the "openwork" character of the near-surface region (that would enhance the $\mathrm{OH} \mathrm{db}$ signal) is likely preferred. However, the presence of micropores at a higher temperature above $131 \mathrm{~K}$ cannot be ruled out. 
Unlike the earlier studies, we have observed this $\mathrm{OH} \mathrm{db}$ signal to persist after annealing a $<50$-nm-thick nc-ice film from 131 to $165 \mathrm{~K}$, i.e., above the temperature of crystallization to cubic ice. This observation appears to support the aforementioned hypothesis that the $\mathrm{OH} \mathrm{db}$ 's are localized on the external surfaces of thin nc-ice and pc-ice films, and suggests that the local structure of the surface of the nc-ice and pc-ice films are similar.

\section{Concluding Remarks}

FTIR Reflection-Absorption Spectroscopy has been used to study the film growth of polycrystalline and noncrystalline ice obtained by vapor deposition over a range of film thickness from 10 to $1500 \mathrm{~nm}$. Simulated spectra of the $\mathrm{OH}$ stretch region $\left(3800-2800 \mathrm{~cm}^{-1}\right)$ based on the Fresnel reflection and Mie scattering theories with the appropriate optical constants obtained from the literature ${ }^{36,38,46}$ are found to give good agreement with the experimental spectra. The intricate nature of the film growth process of ice at different temperatures can be qualitatively characterized as pc-ice or nc-ice, with their respective structures and properties (such as film thickness). Our experiment shows that pc-ice and nc-ice are most likely to form at deposition temperature above $155 \mathrm{~K}$ and below $145 \mathrm{~K}$, respectively. Further analysis using the $\sigma$ - and $\pi$-polarized components of the Fresnel spectra shows that the intensities and shapes of specific bands in a RA spectrum could be significantly affected by migration of interference peaks with increasing film thickness, which in turn complicates spectral identification and population analysis of the corresponding groups in the case of solid-state spectroscopy. The good agreement between the experiment and the Mie spectra for the early stage of film deposition of pc-ice and to a certain extent nc-ice generally confirms the heterogeneous character of the early deposit, which composes of nanoscalesized water aggregates. The experimental confirmation of the Fresnel model upon further film growth illustrates the evolution to a more homogeneous film growth mechanism.

Weak RA peak at $3700-3690 \mathrm{~cm}^{-1}$ attributable to incompletely coordinated $\mathrm{OH}$ groups has also been observed for a majority of pc-ice and nc-ice films deposited under different conditions, indicating that the $\mathrm{OH}$ dangling bonds are an integral structural component of the surfaces of both pc-ice and nc-ice. Although the weak $\mathrm{OH}$ db signals of both pc-ice and nc-ice are essentially independent of the film thickness below $200 \mathrm{~nm}$, the intensity of the $\mathrm{db}$ feature for thicker films (particularly those of nc-ice) appears to be subjected to significant spectral amplification due to the passing of destructive interference patterns through the $\mathrm{OH}$ stretch spectral region over a specific film thickness range. Up to 20 -fold enhancement has been observed in the case of the 1100 nm-thick nc-ice film. Furthermore, the $\mathrm{OH} \mathrm{db}$ signal has been found on pc-ice films deposited at temperature as high as $185 \mathrm{~K}$, and on nc-ice deposited at $131 \mathrm{~K}$ and annealed to $165 \mathrm{~K}$, which is above the temperature of crystallization to cubic ice. This behavior of $\mathrm{OH}$ $\mathrm{db}$ signal is consistent with the picture that the $\mathrm{OH} \mathrm{db}$ 's are most likely located on the external surfaces of the crystalline grains during the early stage of film growth and on the external surface of the film upon further film growth for pc-ice and on the openwork external surfaces in the case of nc-ice. The present work provides us with the basis for further studies of the interactions of volatile organic compounds with ice microphases.

Acknowledgment. This work is supported by the Natural Sciences and Engineering Research Council of Canada. It is our pleasure to acknowledge the skilful workmanship of the entire staff and especially Mr. Richard Forget of the Science Shops at the University of Waterloo. We are in debt to Mr. Dustin Dickens and Dr. James Sloan for sharing their Mie theory code and to Dr. Peter Bernath for useful discussions. We also thank the referee of this paper for useful suggestions, which encourage us to more closely examine the dependence of the $\mathrm{OH} \mathrm{db}$ signal on film thickness. One of us (S.M.) gratefully acknowledges the support of an Ontario Graduate Scholarship.

\section{References and Notes}

(1) Sumner, A. L.; Shepson, P. B. Nature 1999, 398, 230.

(2) Solomon, S.; Garcia, R. R.; Rowland, F. S.; Wuebbles, D. J. Nature 1986, 321, 755 .

(3) Molina, M. J.; Molina, L. T.; Kolb, C. E. Annu. Rev. Phys. Chem. 1996, 47, 327.

(4) Sanford, S. A. In. Polarimetry of the Interstellar Medium; Astron. Soc. Pac. Conf. Series 1996, 97, 29.

(5) Hobbs, P. V. Ice Physics; Clarendon Press: Oxford, 1974; and references therein.

(6) Kohl, I.; Mayer, E.; Hallbrucker, A. Phys. Chem. Chem. Phys. 2000 2(8), 1579.

(7) Jenniskens, P.; Banham, S. F.; Blake, D. F.; McCoustra, M. R. S. J. Chem. Phys. 1997, 107, 1232.

(8) Materer, N.; Starke, U.; Barbieri, A.; Van Hove, M. A.; Somorjai, G. A.; Kroes, G.-J.; Minot, C. Surf. Sci. 1997, 381, 190-210.

(9) Li, J.-C. J. Chem. Phys. 1996, 105, 6733.

(10) Kolesnikov, A. I.; Li, J.-C.; Dong, S.; Bailey, I. F.; Eccleston, R. S.; Hahn, W.; Parker, S. F. Phys. Rev. Lett. 1997, 79, 1869.

(11) Braun, J.; Glebov, A.; Graham, A. P.; Menzel, A.; Toennies, J. P. Phys. Rev. Lett. 1998, 80, 2638.

(12) Hallbrucker, A.; Mayer, E.; Johari, G. P. J. Phys. Chem. 1989, 93, 4986.

(13) Bertie, J. E.; Labbe, H. J.; Whalley, E. J. Chem. Phys. 1969, 50, 4501 .

(14) Hagen, W.; Tielens, A. G. G. M.; Greenberg, J. M. Chem. Phys. 1981, 56, 367.

(15) Rowland, B.; Devlin, J. P. J. Chem. Phys. 1991, 94, 812

(16) Rowland, B.; Kadagathur, N. S.; Devlin, J. P.; Bush, V.; Feldman, T.; Wojcik, M. J. J. Chem. Phys. 1995, 102, 8328.

(17) Rowland, B.; Fisher, M.; Devlin, J. P. J. Chem. Phys. 1991, 95, 1378

(18) Jenniskens, P.; Blake, D. F. Science 1994, 265, 753.

(19) Johari, G. P. Philos. Mag. B 1998, 78, 375.

(20) Kolesnikov, A. I.; Li, J.; Parker, S. F.; Eccleston, R. S.; Loong, C.-K. Phys. Rev. B 1999, 59, 3569.

(21) Narten, A. H.; Venkatesh, C. G.; Rice, S. A. J. Chem. Phys. 1976, $64,1106$.

(22) Leu, M.-T.; Keyser, L. F.; Timonen, R. J. Phys. Chem. 1997, 101, 6259 .

(23) Brown, D. E.; George, S. M.; Huang, C.; Wong, E. K. L.; Rider,

K. B.; Smith, R. S.; Kay, B. D. J. Phys. Chem. 1996, 100, 4988.

(24) Stevenson, K. P.; Kimmel, G. A.; Dohnálek, Z.; Smith, R. S.; Kay, B. D. Science 1999, 283, 1505.

(25) Barabási, A.-L.; Stanley, H. E. Fractal Concepts in Surface Growth; Cambridge University Press: Cambridge, 1995.

(26) Zhdanov, V. P.; Norton, P. R. Surf. Sci. 2000, 449, L228.

(27) Callen, B. W.; Griffiths, K.; Norton, P. R. Surf. Sci. Lett. 1992, 261, L44.

(28) Horn, A. B.; Chesters, M. A.; McCoustra, M. R. S.; Sodeau, J. R. J. Chem. Soc., Faraday Trans. 1992, 88, 1077.

(29) Zondlo, M. A.; Onasch, T. B.; Warshawsky, M. S.; Tolbert, M. A.; Mallick, G.; Arentz, P.; Robinson, M. S. J. Phys. Chem. B 1997, 101, 10887 .

(30) Mitlin, S.; Lemak, A. S.; Chen, Z. Y.; Leung, K. T.; 2002, to be published.

(31) Greenler, R. G. J. Chem. Phys. 1966, 44, 310.

(32) Decius, J. C.; Hexter, R. M. Molecular Vibrations in Crystals; McGraw-Hill: New York, 1977.

(33) McIntyre, J. D. E.; Aspens, D. E. Surf. Sci. 1971, 24, 417.

(34) Born, M.; Wolf, E. Principles of Optics, 6th ed.; Pergamon: New York 1980.

(35) Horn, A. B.; Banham, S. F.; McCoustra, R. S. J. Chem. Soc., Faraday Trans. 1995, 91, 4005.

(36) Toon, O. B.; Tolbert, M. A.; Koehler, B. G.; Middelebrook, A. M. J. Geophys. Res. 1994, 99 (D12), 25, 631.

(37) Hardin, A. H.; Harvey, K. B. Spectrochim. Acta 1973, 29A, 1139.

(38) Leger, A.; Gauthier, S.; Deforneau, D.; Rouan, D. Astron. Astrophys. 1983, 117, 164 
(39) Palik, E. D., Ed. Handbook of the Optical Constants of Solids; Academic: Toronto, 1985.

(40) Weast, R. C., Ed. Handbook of Chemistry and Physics, 64th ed.; CRC Press: Florida, 1983-1984, p E-110.

(41) Buch, V.; Devlin, J. P. J. Chem. Phys. 1999, 110, 3437.

(42) Schriver-Mazzuoli, L.; Schriver, A.; Hallou, A. J. Mol. Spectrosc. 2000, 554, 289.

(43) Robinson, M. S.; Mallick, G.; Spillman, J. L.; Carreon, P. A.; Shalloo, S. App. Optics 1999, 38, 91.

(44) Klein, M. V.; Furtak, T. E. Optics; J. Wiley \& Sons: New York, 1986.

(45) Bohren, C. F.; Huffman, D. R. Absorption and Scattering of Light by Small Particles; Wiley: New York, 1983.
(46) Clapp, M. L.; Miller, R. E.; Worskop, D. R. J. Phys. Chem. 1995, $99,6317$.

(47) Mayer, E.; Pletzer, R. J. Chem. Phys. 1984, 80, 2939.

(48) Bertie, J. E.; Whalley, E. J. Chem. Phys. 1964, 40, 1637.

(49) Turrell, G. Infrared and Raman Spectra of Crystals; Academic: New York 1972.

(50) Barone, S. B.; Zondlo, M. A.; Tolbert, M. A. J. Phys. Chem. 1999, $103,9717$.

(51) Hallbrucker, A.; Mayer, E.; Johari, G. P. J. Phys. Chem. 1989, 93, 4986.

(52) Kouchi, A.; Yamamoto, T. Prog. Crystal Growth and Charact. $1995,30,83$ 